University of Wollongong

Research Online

Faculty of Engineering and Information

Faculty of Engineering and Information

Sciences - Papers: Part A

Sciences

$1-1-2014$

Investigating the optimal passive and active vibration controls of adjacent buildings based on performance indices using genetic algorithms

Muhammad N. S Hadi

University of Wollongong, mhadi@uow.edu.au

Mehmet Uz

University of Wollongong, meuz@uow.edu.au

Follow this and additional works at: https://ro.uow.edu.au/eispapers

Part of the Engineering Commons, and the Science and Technology Studies Commons

Research Online is the open access institutional repository for the University of Wollongong. For further information contact the UOW Library: research-pubs@uow.edu.au 


\title{
Investigating the optimal passive and active vibration controls of adjacent buildings based on performance indices using genetic algorithms
}

\begin{abstract}
This study proposes the optimal passive and active damper parameters for achieving the best results in seismic response mitigation of coupled buildings connected to each other by dampers. The optimisation to minimise the $\mathrm{H} 2$ and $\mathrm{H}$-norms in the performance indices is carried out by genetic algorithms (GAs). The final passive and active damper parameters are checked for adjacent buildings connected to each other under El Centro NS 1940 and Kobe NS 1995 excitations. Using real coded GA in H- norm, the optimal controller gain is obtained by different combinations of the measurement as the feedback for designing the control force between buildings. The propsed method is more effective than other metaheuristic methods and more feasible, although the contol force increased. The results ifn the active control system show that the response of adjacent buildings is reduced in an efficient manner.
\end{abstract}

\section{Keywords}

indices, performance, buildings, adjacent, controls, vibration, active, passive, algorithms, optimal, genetic, investigating

\section{Disciplines}

Engineering | Science and Technology Studies

\section{Publication Details}

Hadi, M. N. S. \& Uz, M. (2015). Investigating the optimal passive and active vibration controls of adjacent buildings based on performance indices using genetic algorithms. Engineering Optimization, 47 (2), 265-286. 


\section{PROOF COVER SHEET}

Author(s): Muhammad N.S. Hadi

Article title: Investigating the optimal passive and active vibration controls of adjacent buildings based on performance indices using genetic algorithms

Article no: GENO887704

Enclosures: 1) Query sheet

2) Article proofs

Dear Author,

1. Please check these proofs carefully. It is the responsibility of the corresponding author to check these and approve or amend them. A second proof is not normally provided. Taylor \& Francis cannot be held responsible for uncorrected errors, even if introduced during the production process. Once your corrections have been added to the article, it will be considered ready for publication.

Please limit changes at this stage to the correction of errors. You should not make insignificant changes, improve prose style, add new material, or delete existing material at this stage. Making a large number of small, non-essential corrections can lead to errors being introduced. We therefore reserve the right not to make such corrections.

For detailed guidance on how to check your proofs, please see http://journalauthors.tandf.co.uk/production/checkingproofs.asp.

2. Please review the table of contributors below and confirm that the first and last names are structured correctly and that the authors are listed in the correct order of contribution. This check is to ensure that your name will appear correctly online and when the article is indexed.

\begin{tabular}{|l|l|l|l|l|}
\hline Sequence & Prefix & Given names(s) & Surname & Suffix \\
\hline 1. & & Muhammad N.S. & Hadi & \\
\hline 2. & & Mehmet E. & Uz & \\
\hline
\end{tabular}


Queries are marked in the margins of the proofs.

\section{AUTHOR QUERIES}

General query: You have warranted that you have secured the necessary written permission from the appropriate copyright owner for the reproduction of any text, illustration, or other material in your article. (Please see http://journalauthors.tandf.co.uk/preparation/permission.asp.) Please check that any required acknowledgements have been included to reflect this.

\begin{tabular}{|c|l|}
\hline QUERY NO. & QUERY DETAILS \\
\hline AQ1 & $\begin{array}{l}\text { "Shayeghi (2009)" has been changed to Shayeghi, Eimani Kalasar, and } \\
\text { Shayeghi (2009) to match the entry in the reference list. Please confirm that } \\
\text { this is correct and provide revisions if neede }\end{array}$ \\
\hline AQ2 & $\begin{array}{l}\text { The reference "Hadi and Arfiadi (2011)" is cited in the text but is not listed in } \\
\text { the reference list. Please either delete in-text citation or provide full reference } \\
\text { details following journal styl }\end{array}$ \\
\hline AQ3 & $\begin{array}{l}\text { The spelling of Name for "Bektas and Nigdeli (2011)" has been changed to } \\
\text { Bekdas and Nigdeli (2011) to match the entry in the reference list. Please } \\
\text { confirm that this is correct and provide revisions if needed }\end{array}$ \\
\hline AQ4 & $\begin{array}{l}\text { The reference "Pourzeynali et al. (2006)" is cited in Tables } 8 \text { and } 9 \text { but is not } \\
\text { listed in the reference list. Please either delete in-text citation or provide full } \\
\text { reference details following journal styl }\end{array}$ \\
\hline
\end{tabular}




\section{How to make corrections to your proofs using Adobe Acrobat}

Taylor \& Francis now offer you a choice of options to help you make corrections to your proofs. Your PDF proof file has been enabled so that you can edit the proof directly using Adobe Acrobat. This is the simplest and best way for you to ensure that your corrections will be incorporated. If you wish to do this, please follow these instructions:

1. Save the file to your hard disk.

2. Check which version of Adobe Acrobat you have on your computer. You can do this by clicking on the "Help" tab, and then "About."

If Adobe Reader is not installed, you can get the latest version free from http://get.adobe.com/reader/.

- If you have Adobe Reader 8 (or a later version), go to "Tools"/“Comments \& Markup"/ "Show Comments \& Markup."

- If you have Acrobat Professional 7, go to "Tools"/ "Commenting"/“Show Commenting Toolbar."

3. Click "Text Edits." You can then select any text and delete it, replace it, or insert new text as you need to. If you need to include new sections of text, it is also possible to add a comment to the proofs. To do this, use the Sticky Note tool in the task bar. Please also see our FAQs here: http://journalauthors.tandf.co.uk/production/index.asp.

\section{T/ Text Edits \\ [T Iext Edits Tool \\ 国 Replace Selected Tert \\ T] Highlight Selected Text \\ 5. Add Note To Selected Text \\ T. Insert Text At Cursor \\ T] Underline Selected Text \\ Cross Out Text for Deletion

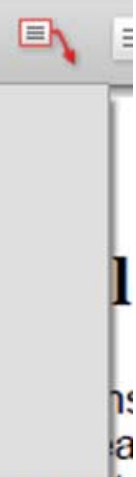

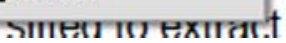

4. Make sure that you save the file when you close the document before uploading it to CATS using the "Upload File" button on the online correction form. A full list of the comments and edits you have made can be viewed by clicking on the "Comments" tab in the bottom left-hand corner of the PDF. 


\title{
RESEARCH ARTICLE
}

\section{Investigating the optimal passive and active vibration controls of adjacent buildings based on performance indices using genetic algorithms}

\author{
Muhammad N.S. Hadi* and Mehmet E. Uz \\ School of Civil, Mining and Environmental Engineering, University of Wollongong, Wollongong, Australia
}

(Received 2 May 2013; accepted 4 December 2013)

\begin{abstract}
This study proposes the optimal passive and active damper parameters for achieving the best results in seismic response mitigation of coupled buildings connected to each other by dampers. The optimization to minimize the $\mathrm{H}_{2}$ and $\mathrm{H}_{\infty}$ norms in the performance indices is carried out by genetic algorithms (GAs). The final passive and active damper parameters are checked for adjacent buildings connected to each other under El Centro NS 1940 and Kobe NS 1995 excitations. Using real coded GA in $H_{\infty}$ norm, the optimal controller gain is obtained by different combinations of the measurement as the feedback for designing the control force between the buildings. The proposed method is more effective than other metaheuristic methods and more feasible, although the control force increased. The results in the active control system show that the response of adjacent buildings is reduced in an efficient manner.
\end{abstract}

Keywords: seismic effects; passive control; active control; genetic algorithms

\section{Introduction}

Buildings with passive, active, semi-active and hybrid control devices have been investigated with great interest during the past decades. Many studies have been carried out on dissipative links (Hadi and Arfiadi 1998; Kim, Ryu, and Chung 2006; Westermo 1989; Xu, He, and Ko 1999; Yang, Xu, and Lu 2003; Zhu, Wen, and Iemura 2001), active (Aldemir 2010; Arfiadi 2000; Arfiadi and Hadi 2000, 2001, 2006), semi-active and hybrid (Christenson et al. 2003; Dyke et al. 1996; Ok, Song, and Park 2009; Spencer and Sain 1997) devices to mitigate the response of buildings. Furthermore, many structural control concepts have been implemented in various scientific and engineering problems. In recent years, several powerful metaheuristic optimization algorithms have been proposed and in the field of structural engineering their many successful applications have been reported in the literature. Metaheuristic methods such as genetic algorithm (GA), particle swarm optimization (PSO) (Gholizadeh 2013; Leung and Zhang 2009), ant colony optimization (ACO), simulated annealing, big bang-big crunch and harmony search (HS) (Bekdas and Nigdeli 2011; Fadel Miguel, Lopez, and Miguel 2013; Gholizadeh and Barzegar 2012) have been investigated to solve optimization problems. For optimization of passive dampers such as tuned mass damper (TMD) and viscous elastic damper (VED), metaheuristic methods have

*Corresponding author. Email: mhadi@uow.edu.au 
been investigated. Owing to their simple concept, easy implementation and quick convergence, metaheuristic methods such as ACO, PSO and HS have gained much attention and have a wide variety of applications in real and academic engineering cases.

GA has some attractive characteristics compared with other evolutionary algorithms. For example, PSO has a memory to keep the knowledge of good solutions although the population changes. In GA, it is possible to insert a new population to increase the variety of individuals once the previous knowledge on the problem has been destroyed. The main drawback of ACO lay in handling continuous space problems with large dimension and great numerical precision. Real coding in GA solves continuous optimization problems, whereas binary coding is not appropriate in GA. Obtaining a closed form solution in GA is not as easy as HS optimization for the actual system. GA- $H_{2}$ and GA- $H_{\infty}$ are suitable for handling this problem without converting a structural model to a single mode model. Control algorithms developed for passive and active control have been directly useful for developing other recent control strategies. To check the accuracy of the mechanical model of the damped structure, for example, Lee et al. (2006), Pourzeynali, Lavasani, and Modarayi (2007), Arfiadi and Hadi (2011), Bekdas and Nigdeli (2011), Fadel Miguel, Lopez, and Miguel (2013) and Bekdas and Nigdeli (2013) analysed the same examples used in the study and compared their results with the GA method proposed by Hadi and Arfiadi (1998).

The most common optimal control algorithms, such as the linear quadratic regulator (LQR), $H_{2}, H_{\infty}$ and fuzzy control, can be chosen by combining GAs. Passive control systems that do not require any external power are widely used to reduce the response of buildings. Optimal design of the passive dampers for multi-degree of freedom (MDOF) structures was investigated by Hadi and Arfiadi (1998). The study used optimization to minimize the $\mathrm{H}_{2}$ norm transfer function using a binary coded GA. The optimum value of damper parameters can be found without specifying which modes should be controlled (Hadi and Arfiadi 1998). Ahlawat and Ramaswamy (2003) proposed an optimum design of dampers using a multi-objective version of the GA. Although a passive control technique is still considered owing to its simplicity, semi-active and active control systems nowadays have received considerable attention.

In semi-active control methods, Dyke et al. (1996), Ni, Ko, and Ying (2001) and Yoshida and Dyke (2004) investigated the effectiveness of magnetorheological (MR) dampers for civil engineering structures. Ok, Song, and Park (2009) developed an optimal design of semi-active dampers using multi-objective optimization. Despite the recent developments of control strategies such as semi-active control, more research is required in the area of active structural control (Pourzeynali, Lavasani, and Modarayi 2007). Bharti, Dumne, and Shrimali (2010) studied seismic response mitigation of adjacent buildings under semi-active control strategies. Based on the results of their study, MR dampers in semi-active control strategies are effective devices to control the response of both buildings under ground motion. In the active vibration control area, Arfiadi and Hadi (2001) improved a simple optimization procedure with the help of GAs to design the control force. They used a static output feedback controller utilizing the measurement output. In this case, the control force is obtained by multiplying the measurement with the gain matrix (Arfiadi and Hadi 2001). To obtain the best results in the reduction of the structures, combined application of the GAs and fuzzy logic has been proposed to design and optimize the different parameters of active dampers by Pourzeynali, Lavasani, and Modarayi (2007).

In this study, a global optimization method which is a modification of the GA adopted by Arfiadi and Hadi $(2000,2011)$ was used to optimize the parameters of passive and active dampers in a coupled building. The optimum parameters of a damped main system of adjacent buildings subject to excitations have not been intensely investigated by optimization methods. The method is applied to design viscoelastic dampers in the passive control system. For the passive control system, the binary coded GA is usually sufficient to solve the problems. For the active control system, in order to increase the capability of the viscoelastic dampers, an actuator is installed 
in the top floor of a coupled building to drive the control force to the buildings. In the active control system, the real coded GA is appropriate to find the domain of the controller gain, which is usually unknown. The objective of this study is to investigate the efficacy of optimal passive damper parameters and to obtain optimum stable controllers for active dampers using both binary and real GA for seismic response mitigation. The responses of the adjacent buildings are compared with the corresponding uncontrolled individual buildings. The performance of the controllers used in this study is also compared under $\mathrm{H}_{2}$ and $H_{\infty}$ optimizations. The influence of damper location and the regulated outputs to be minimized on the control performance are also studied.

\section{Theoretical background of system model}

Consider two $n$ - and $m$-storey shear buildings with active dampers installed at all floors between buildings as shown in Figure 1. The equation of motion of an MDOF linear system subjected to a single seismic excitation $X_{g}$ and control actions $U(t)$ acting on a damper system is written as shown in Equations (1) and (2).

The equation of motion of Building A:

$$
M_{1} \ddot{X}_{1}+C_{1} \dot{X}_{1}+K_{1} X_{1}=-M_{1} E_{1} \ddot{X}_{g}
$$

The equation of motion of Building B:

$$
M_{2} \ddot{X}_{2}+C_{2} \dot{X}_{2}+K_{2} X_{2}=-M_{2} E_{2} \ddot{X}_{g}
$$

Equations (1) and (2) should be solved simultaneously. When passive and active control are considered, a convenient matrix form can be developed by first combining these equations, leading

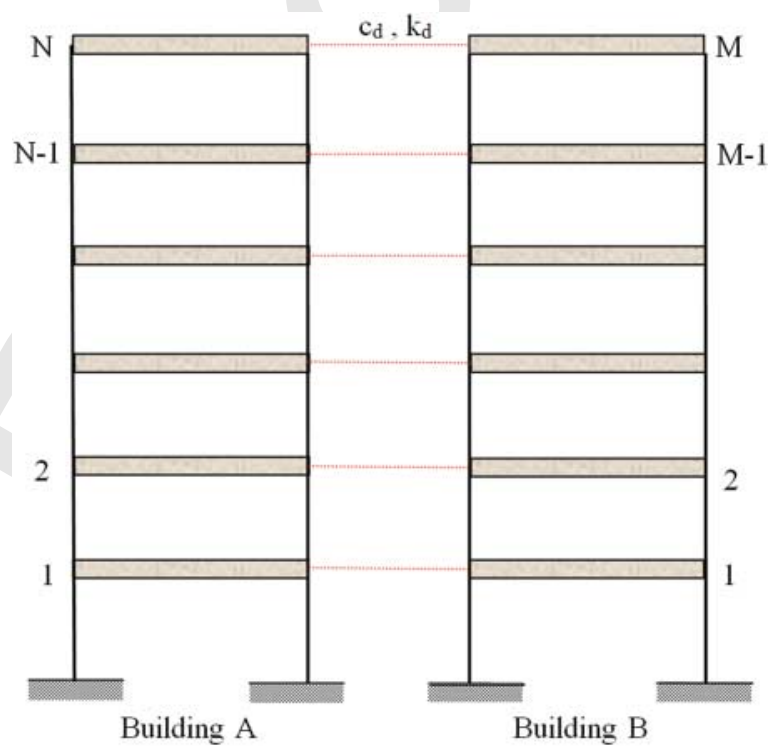

Figure 1. $\quad N$ and $M$ storey shear buildings with viscoelastic dampers. 
to the expression

$$
\begin{gathered}
{\left[\begin{array}{cc}
M_{1} & 0 \\
0 & M_{2}
\end{array}\right]\left\{\begin{array}{l}
\ddot{X}_{1} \\
\ddot{X}_{2}
\end{array}\right\}+\left(\left[\begin{array}{cc}
C_{1} & 0 \\
0 & C_{2}
\end{array}\right]+\left[\begin{array}{ccc}
c_{d(m, m)} & 0_{(m, s)} & -c_{d(m, m)} \\
0_{(s, m)} & 0_{(s, m)} & 0_{(s, m)} \\
-c_{d(m, m)} & 0_{(m, s)} & c_{d(m, m)}
\end{array}\right]\right)\left\{\begin{array}{l}
\dot{X}_{1} \\
\dot{X}_{2}
\end{array}\right\}} \\
+\left(\left[\begin{array}{cc}
K_{1} & 0 \\
0 & K_{2}
\end{array}\right]+\left[\begin{array}{ccc}
k_{d(m, m)} & 0_{(m, s)} & -k_{d(m, m)} \\
0_{(s, m)} & 0_{(s, m)} & 0_{(s, m)} \\
-k_{d(m, m)} & 0_{(m, s)} & k_{d(m, m)}
\end{array}\right]\right)\left\{\begin{array}{l}
X_{1} \\
X_{2}
\end{array}\right\}=\left[\begin{array}{c}
-M_{1} E_{1} \\
-M_{2} E_{2}
\end{array}\right] \ddot{X}_{g}+\left[\begin{array}{l}
P_{1} \\
P_{2}
\end{array}\right] U(t)
\end{gathered}
$$

The equation of motion in Equation (3), which is explained in Appendix 1, can be transformed into first order state equations. $c_{d(m, m)}$ and $k_{d(m, m)}$ are $(m \times m)$ diagonal matrices of the additional damping and stiffness matrices due to the instillation of the fluid dampers. The subscript $s$ in Equation (3) denotes the $(n-m)$ difference in the number of storeys of the buildings. By defining the state vector $X=\left\{\begin{array}{llll}X_{1} & X_{2} & \dot{X}_{1} & \dot{X}_{2}\end{array}\right\}^{T}$, Equation (3) may be rewritten as

$$
\left\{\begin{array}{l}
\ddot{X}_{1} \\
\ddot{X}_{2}
\end{array}\right\}=-M^{-1} C\left\{\begin{array}{l}
\dot{X}_{1} \\
\dot{X}_{2}
\end{array}\right\}-M^{-1} K\left\{\begin{array}{l}
X_{1} \\
X_{2}
\end{array}\right\}+M^{-1}\left\{\begin{array}{l}
-M_{1} E_{1} \\
-M_{2} E_{2}
\end{array}\right\} \ddot{X}_{g}+M^{-1}\left\{\begin{array}{l}
P_{1} \\
P_{2}
\end{array}\right\} U(t)
$$

From Equation (4), the velocity of the state vector can be obtained as

$$
\dot{X}=\left\{\begin{array}{l}
\dot{X}_{1} \\
\dot{X}_{2} \\
\ddot{X}_{1} \\
\ddot{X}_{2}
\end{array}\right\}=\left[\begin{array}{cc}
0_{(n+m) \times(n+m)} & \mathrm{I}_{(n+m) \times(n+m)} \\
-M^{-1} K & -M^{-1} C
\end{array}\right]\left\{\begin{array}{l}
X_{1} \\
X_{2} \\
\dot{X}_{1} \\
\dot{X}_{2}
\end{array}\right\}+\left[\begin{array}{c}
0_{(n+m) \times 1} \\
M^{-1} E
\end{array}\right] \ddot{X}_{g}(t)+\left[\begin{array}{c}
0_{(n+m) \times n_{a}} \\
M^{-1} D
\end{array}\right] U(t)
$$

where

$$
\begin{aligned}
D & =\left[\begin{array}{c}
P_{1} \\
0_{\left(s, n_{a}\right)} \\
P_{2}
\end{array}\right], E=\left[\begin{array}{l}
-M_{1} E_{1} \\
-M_{2} E_{2}
\end{array}\right], A=\left[\begin{array}{cc}
0_{(n+m) \times(n+m)} & \mathrm{I}_{(n+m) \times(n+m)} \\
-M^{-1} K & -M^{-1} C
\end{array}\right], H=\left[\begin{array}{c}
0_{(n+m) \times 1} \\
M^{-1} E
\end{array}\right], \\
B & =\left[\begin{array}{c}
0_{(n+m) \times n_{a}} \\
M^{-1} D
\end{array}\right]
\end{aligned}
$$

where $E_{1}$ and $E_{2}$ are $n \times 1$ and $m \times 1$ unit matrices. $P_{1}$ and $P_{2}$ are given in Appendix 1. Here, $\mathbf{I}$ is an identity matrix. The equation of motion in Equation (5) can be arranged as

$$
\dot{X}=A X+B U(t)+H \ddot{X}_{g}(t)
$$

Since only earthquake loading is considered, the equations of motion can be written as

$$
\dot{X}=A X+H \ddot{X}_{g}(t)
$$

The objective is to find the optimum values of the damper parameters (i.e. damping and stiffness) using the following feedback controllers.

\section{Optimal feedback controllers}

For the optimization of passive and active control problems between adjacent buildings, several optimization methods based on the chosen objective function have been synthesized in this study. The $H_{2}$ and $H_{\infty}$ norms are considered as objective functions in the modern control theory. 


\subsection{LQR Optimization with Full State Feedback}

For the equation of motion in Equation (4), the performance index is a combination of state vector and control force as

$$
J=\int_{0}^{t}\left(X^{T} Q X+U^{T} R U\right) \mathrm{d} t \rightarrow \min \Rightarrow U(t)=-G X
$$

where $Q$ is a symmetric positive semi-definite matrix, $R$ is a symmetric positive definite matrix, and $t$ is the final time to be considered. The importance of each term in the integrand can be imposed with $Q$ and $R$ weight matrices. If the coefficients in the matrix $Q$ are large, then the response $X$ is reduced substantially, with the consequence of having large control force. On the other hand, if the coefficients in the matrix $R$ are large, then the required control force will be small, but the reduction in the response of buildings might not be substantial. To minimize the cost function in Equation (9), the constraint is the equation of motion in Equation (10):

$$
R=\left[\begin{array}{llllll}
1 & 0 & 0 & 0 & 0 & 0 \\
0 & 1 & 0 & 0 & 0 & 0 \\
0 & 0 & 1 & 0 & 0 & 0 \\
0 & 0 & 0 & 1 & 0 & 0 \\
0 & 0 & 0 & 0 & 1 & 0 \\
0 & 0 & 0 & 0 & 0 & 1
\end{array}\right], Q=\left[\begin{array}{ll}
\mathrm{I}_{12 \times 12} & 0_{12 \times 12} \\
0_{12 \times 12} & \mathrm{I}_{12 \times 12}
\end{array}\right]
$$

In optimal control forms, the resulting gain matrix $G$ can be obtained as $G=1 / 2 R^{-1} B^{T} P$. The gain matrix, $G$, is obtained by using the 'lqr' command in Matlab. $P$ is the Riccati matrix, which can be solved by a Riccati equation in Equation (11):

$$
P A-\frac{1}{2} P B R^{-1} B^{T} P+A^{T} P+2 Q=0
$$

The resulting control force becomes

$$
\dot{X}=\left[A-\frac{1}{2} B R^{-1} B^{T} P\right] X+H \ddot{X}_{g}(t)
$$

After rearranging Equation (12), the equation of motion of buildings with the control parameters can be rewritten as

$$
\dot{X}=(A-B G) X+H \ddot{X}_{g}
$$

Equation (13) can be solved under the different ground motions to obtain the response of adjacent buildings.

\section{2. $\mathrm{H}_{2}$ Optimization}

The use of the $\mathrm{H}_{2}$ optimization procedure for the structural response under earthquake loading has been considered by many researchers in civil engineering applications (Dyke et al. 1996; Holland 1992; Spencer, Suhardjo, and Sain 1994). The objective of $H_{2}$ methods is to minimize the transfer function of the closed loop system from the external disturbance to a certain controlled output. The $\mathrm{H}_{2}$ norm can be determined by

$$
\left\|\hat{\mathrm{G}}_{\mathrm{xw}}\right\|_{2}=\left(\frac{1}{2 \pi} \int_{-\infty}^{\infty} \operatorname{tr}\left(\hat{\mathrm{G}}_{\mathrm{xw}}(\mathrm{j} \omega) \hat{\mathrm{G}}_{\mathrm{xw}}^{*}(\mathrm{j} \omega) \mathrm{d} \omega\right)\right)^{1 / 2}
$$

where $\left\|\hat{\mathrm{G}}_{\mathrm{xw}}\right\|_{2}$ is the $H_{2}$ norm transfer function from the external disturbance $w=\ddot{X}_{g}$ to the controlled output $x, \omega$ and $j$ are frequency and imaginary, and * and $t r$ represent the complex 
conjugate transpose and the trace, respectively. The regulated output $x$ as the response to be kept small is chosen in relation to the performance index to be minimized.

$$
x=C_{w} X
$$

The $H_{2}$ norm transfer function from $w$ to $x$ can be computed using (Holland 1992; Lublin, Grocott, and Athans 1996)

$$
\begin{aligned}
& \left\|\hat{G}_{x w}\right\|_{2}=\left[\operatorname{tr}\left(C_{w} L_{c} C_{w}^{T}\right)\right]^{1 / 2}=\left[H^{T} L_{o} H\right]^{1 / 2} \\
& \left\|\hat{G}_{x w}\right\|_{2}=\left[\operatorname{tr}\left(C_{w} L_{c} C_{w}^{T}\right)\right]^{1 / 2}=\left[\operatorname{tr}\left(H^{T} L_{o} H\right)\right]^{1 / 2}
\end{aligned}
$$

where $L_{c}$ and $L_{o}$, which can be determined from the Lyapunov equations, are the controllability and observability Gramians, respectively.

$$
\begin{array}{r}
A L_{c}+L_{c} A^{T}+H H^{T}=0 \\
A^{T} L_{o}+L_{o} A+C_{w}^{T} C_{w}=0
\end{array}
$$

Note that displacements, velocities and absolute accelerations of adjacent buildings can be included in the controlled output defined in Equation (15). By choosing the appropriate entry in the regulation matrix, certain regulated output that needs to be minimized can be imposed. For example, if the regulated output is taken as the relative displacement of the floors with respect to the ground, the matrix $C_{w}$ can be chosen as

$$
C_{w}=\left[\begin{array}{ll}
\mathrm{I}_{(N+M) \times(N+M)} & 0_{(N+M) \times(N+M)}
\end{array}\right]
$$

where $\mathbf{I}$ is an identity matrix, 0 is a matrix containing zeros, and $N$ and $M$ are the total degrees of freedom of both Building A and Building B. Furthermore, for feedback control in active control systems, matrix $A$ in Equations (18) and (19) will be replaced with $A_{\mathrm{cl}}$ as shown in Appendix 1 (A9). Hence, the optimization problem is to find the optimum of damper parameters, using GA as an optimization tool.

\section{3. $H_{\infty}$ Optimization}

To quantify the transfer functions the $H_{2}$ and $H_{\infty}$ norms are usually used. In $H_{\infty}$ controllers, the objective is to minimize the infinity norm of the transfer function from external disturbances to the regulated outputs. The $H_{\infty}$ norm can be cast in an iterative manner. In this case, the Hamiltonian matrix can be defined as

$$
\mathrm{H}=\left[\begin{array}{cc}
A+H R^{-1} D^{T} C_{w} & H R^{-1} H^{T} \\
-C_{w}^{T}\left(\mathbf{I}+D R^{-1} D^{T}\right) C_{w} & -\left(A+H R^{-1} D^{T} C_{w}\right)^{T}
\end{array}\right]
$$

where $R=\gamma^{2} \mathbf{I}-D^{T} D$. In this study, eigenvalues of this matrix in Equation (21) are symmetrical about the real and imaginary axes with $D=0$. The $H_{\infty}$ norm can be computed in the following bisection algorithm.

(a) Select $\gamma_{\mathrm{u}}, \gamma_{1}$ so that $\gamma_{1} \leq\left\|\hat{G}_{\infty}\right\| \leq \gamma_{\mathrm{u}}$

(b) If $\left(\gamma_{\mathrm{u}}-\gamma_{1}\right) / \gamma_{1} \leq$ specified level (Tol.)

Yes Stop $\left(\left\|\hat{G}_{\infty}\right\| \approx 1 / 2\left(\gamma_{\mathrm{u}}+\gamma_{1}\right)\right)$

Otherwise go to Step(c) 
(c) Set $\gamma=\left(\gamma_{\mathrm{u}}+\gamma_{1}\right) / 2$ and test if $\left\|\hat{G}_{\infty}\right\| \leq \gamma$ using $\lambda_{i}(\boldsymbol{H})$

(d) If $\lambda_{i}(\boldsymbol{H}) \quad j \in R j \in$ then set $\gamma_{l}=\gamma$, otherwise set $\gamma_{\mathrm{u}}=\gamma$ and go to Step (b)

The resulting $\gamma$ is the $H_{\infty}$ norm to be determined. In the numerical solution, the computation of $H_{2}$ norm in Equation (14) and $H_{\infty}$ norm in the bisection algorithm can be obtained using lyap and norm commands in the Matlab Control System Toolbox. The controller gains are then solved using a genetic-based optimizer.

\section{Mechanics of genetic algorithms}

The GA is a stochastic algorithm-based random search method that imitates natural phenomena for its search operations. GAs have become effective tools for solving optimization problems in engineering applications. A binary string or a real number can represent a candidate design variable in a GA. During its early development, GA used binary coding to represent the design variable (Goldberg 1989; Holland 1992). Although binary coded GAs have been successfully applied to solve the optimization of complex problems, they have some drawbacks because of the unknown domain of the design variables in active control (Arfiadi and Hadi 2001). These drawbacks make binary coded GAs relatively difficult to solve. Real coded GAs that use real numbers to represent design variables were also developed, and are capable of exploring a large domain, or even the unknown domain of the controller in the case of active control systems (Herrera, Lozano, and Verdegay 1998; Michalewicz 1996).

GAs start with a population of random candidates and advance towards better chromosomes by applying genetic operators. After initialization, the fitness of candidates is calculated according to the objective function. The GA process is shown in Table 1 . The candidates undergo a selection process based on the fitness of each individual. In the selection process, the better chromosomes generate higher values than others and are placed in the mating pool. Every individual (chromosome) of the design variables (genes) in the population undergoes genetic evolution through crossover and mutation by a defined fitness function. In this study, the roulette-wheel selection procedure maps the population in conjunction with the elitist strategy. Using an elitist strategy ensures that the best individual in each generation is passed to the next generation. After selection, crossover and mutation, a new population is generated in both coding GAs. This new population repeats the same process iteratively until a defined condition is reached. Details of the structure of GAs are given in the following subsections. In this study, both binary and real coding are used for

Table 1. Structure of the genetic algorithm.

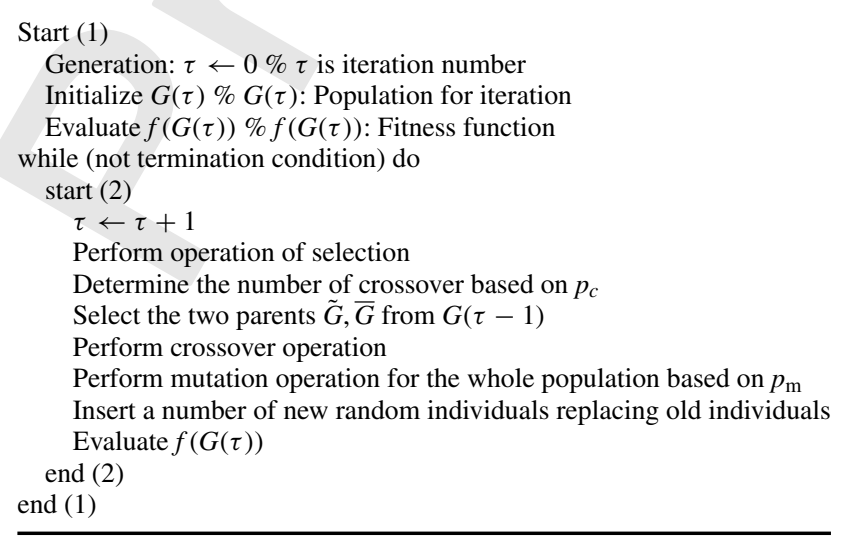


adjacent buildings connected by passive dampers, while real coding GA is only used for active control. Both the binary and real coding GAs are presented in brief here.

\subsection{Design variables in genetic algorithms}

In the binary coding GA, a chromosome can be represented using a binary string with 1 or 0 . The mechanics of GA starts with the creation of an initial population of chromosomes as a set of candidates of initial design variables. The length of subchromosome (nbits) can be calculated based on upper $\left(U_{i}\right)$ and lower $\left(L_{i}\right)$ bound values and the significant digit $\left(p_{i}\right)$ of each design variable ( $i$ th). Details of the length of the individual are explained by Arfiadi (2000). In real coding GAs, as the candidates of design variables, vectors of real numbers are used to represent individuals. For example, $r=\left(n_{a} \times m_{a}\right)$ controller gains by having both the $n_{a}$ actuators to drive the control force and the $m_{a}$ measurements to be obtained for feedback. The population of the individuals can be shown as follows

$$
\begin{aligned}
G^{1} & =\left[\begin{array}{lllll}
g_{1}^{1} & g_{2}^{1} & . & . & g_{r}^{1}
\end{array}\right] \\
G^{2} & =\left[\begin{array}{lllll}
g_{1}^{2} & g_{2}^{2} & . & . & g_{r}^{2}
\end{array}\right] \\
& \vdots \\
G^{p} & =\left[\begin{array}{lllll}
g_{1}^{p} & g_{2}^{p} & . & . & g_{r}^{p}
\end{array}\right]
\end{aligned}
$$

where $g_{j}^{i}$ represents an element of the $i$ th individual of the $j$ th design variable.

\subsection{Fitness evaluation and selection procedure}

In binary coding, after initialization, the binary strings are converted into a real number of a design variable using Equation (23) (Hadi and Arfiadi 1998):

$$
r_{i}=L_{i}+\frac{t_{i} \times\left(U_{i}-L_{i}\right)}{2^{\text {nbits }}-1}
$$

where $r_{i}$ is the real number of a design variable, and $t_{i}$ is an integer mapping of a binary string, which can be obtained using

$$
t_{i}=\sum_{j=0}^{l_{m}} h_{j} \times 2^{j}
$$

in which the binary bit $h_{j}$ is $\left[\begin{array}{lllll}h_{r} & h_{r-1} & \ldots & h_{1} & h_{0}\end{array}\right]$ and $l_{m}$ is the length of subchromosome to represent a particular design variable -1 . After determining the real value of each design variable in the population, the fitness of each individual can be obtained according to the defined objective function. In real coding, real numbers to represent design variables can directly be substituted into the fitness function. Each individual in the fitness function calculates the fitness of each individual in which the fitness is $\mathrm{H}_{2}$ or $H_{\infty}$ norms. The positive fitness function is needed in both binary and real coding GAs; the problem of minimization is converted such that the fitness has a positive value as follows

$$
f=\alpha \times(1 / J)
$$

where $J$ is the objective function and $\alpha$ is a constant value to scale the fitness function. The conversion of the objective function in the form of Equation (25) is possible with the assumption that the $\mathrm{H}_{2}$ and $\mathrm{H}_{\infty}$ norm transfer functions are positive definite. An active control system may cause instability if not designed properly. The simplest way to avoid instability of the structure 
is to ensure that the eigenvalues of the closed loop system are placed on the left side of the splane. This constraint is incorporated into the fitness function by setting the fitness of individuals having positive real-part eigenvalues to a very small positive value that can still be accepted by the computer. If the system has a negative real part of the eigenvalue then the system is called asymptotically stable (Michalewicz 1996).

The selection procedure used in this study is a roulette-wheel selection procedure in both binary and real coding GAs. The reproduction is processed in two stages. In the first stage, the fitness of each individual is evaluated and the sum of the fitness is calculated to determine the probability of selecting each chromosome. In the second stage, the selection mechanism places the highly fitted chromosomes in the mating pool. To perform this stage, the cumulative probabilities of selection of each individual are calculated (Arfiadi and Hadi 2001, 2011; Hadi and Arfiadi 1998). Each random number $a_{j}(j=1,2, \ldots$ popsize) between 0 and 1 is compared with the cumulative probability of selection of each chromosome $q_{j}$, and when the random number $a_{j} \leq q_{j}$, the $j$ th individual will be selected. Here, popsize is the number of individuals in the population. The best individual is always selected in the next generation using an elitist strategy by simply passing the individual with the best fitness into the next generation. After selection has been carried out, the crossover and mutation operations are performed.

\subsection{Crossover and mutation}

In this study, a simple crossover is used as the main crossover operator for binary coding. Simple crossover randomly picks two parents from the mating pool. Simple crossover exchanges genetic information for one random split point in the chromosomes. According to Figure 2, two chromosomes are selected for a simple crossover operation if the random number is smaller than the crossover rate $p_{c}$. Details of a simple crossover operation are given in Holland (1992) and Michalewicz (1996). For real coded GA, crossover is applied according to the vector value of real numbers. Balance crossover of the main crossover operators is used in real coded GA. Balance crossover is very similar to the heuristic crossover for real coded GA. Every pair of parents in the population based on the crossover rate (probability of crossover) is selected to apply the crossover operator. Balance crossover may be produced from both sides, such that the resulting offspring are

$$
\begin{aligned}
& \tilde{G}^{\prime}=a(\tilde{G}-\bar{G})+\tilde{G} \\
& \bar{G}^{\prime}=a(\bar{G}-\tilde{G})+\bar{G}
\end{aligned}
$$

where $\bar{G}$ and $\tilde{G}$ are selected parents in the population, $\bar{G}^{\prime}$ and $\tilde{G}^{\prime}$ are the resulting offspring, and $a$ is a random number between 0 and 1 . This random number affects all design variables in the selected parents. This type of crossover operator helps the offspring's results to fall into a larger domain than the parents' domain in active control problems to explore the unknown domain of the gains. After a simple crossover in the binary coding, mutation is performed in this study. The mutation is a random operator whereby values of an element within a chromosome are changed. $p_{m} \times$ (ntbits $\times$ popsize) bits will undergo mutation if a random number $n_{r}$ from the range $(0-1)<p_{m}$. Here, ntbits is the total length of subchromosomes (nbits). In this case,

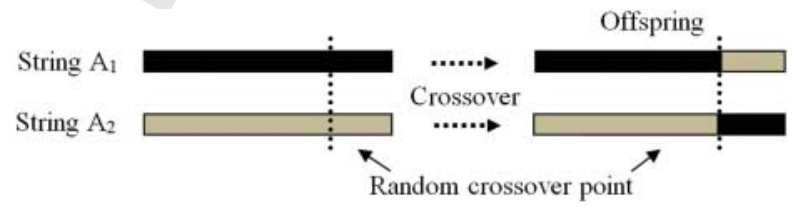

Figure 2. Illustration of a simple crossover operation. 


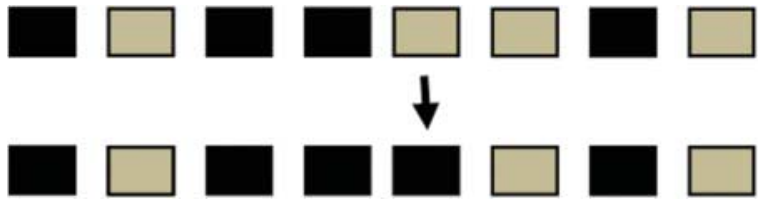

Figure 3. Illustration of mutation.

mutation is performed with the probability of mutation $p_{m}$. To maintain the variability of the population, mutation in binary coding is the random changing of $0 \mathrm{~s}$ to $1 \mathrm{~s}$ and vice versa. Figure 3 shows the mutation operation. For real coded GA the second modification operators are usually employed as simple mutation, non-uniform mutation, multi-non-uniform mutation and boundary mutation. After a balance crossover, a simple mutation is employed as a genetic operator. A certain individual is modified as the resulting individual $\hat{G}=\left[\begin{array}{lllll}\hat{g}_{1} & \hat{g}_{2} & \ldots & \hat{g}_{i}^{\prime} & \hat{g}_{r}\end{array}\right]$, in which $\hat{g}^{\prime}=2 \times a_{r} \times \hat{g}_{i}$ are modified elements in the chromosome after mutation; $a_{r}$ is a random number between 0 and 1 , and the random number does not have the same value.

\section{Application}

Three numerical examples are performed on an i7-2630QM 2.9 GHz computer running MATLAB $\mathrm{R} 2009 \mathrm{~b}$ for two cases. The first example is adjacent buildings connected by passive damper systems. The second is adjacent buildings using active control systems. Finally, the proposed method is compared with the other studies in the literature. In this study, the parameters used in numerical examples by Arfiadi (2000) are slightly modified. Furthermore, for the passive control system, both binary and real coding are used and compared to optimize the passive device parameters. For the active control system, real coded GA is used with the regulated output defined to obtain the controller gains. Hence, the controller gains based on the availability measurement outputs are obtained. In this study, several controllers are designed by choosing different combinations of measurements as feedback.

\subsection{Genetic algorithm parameters and modification}

The GA parameters used in this study are separated into two sections, as shown in Table 2. The simple GA procedure is also slightly modified here. The problems are formulated using linear programming first, and GA based on roulette-wheel selection, arithmetic crossover and uniform mutation was developed and applied next. GA can handle the nonlinear behaviour of the structure caused by either large displacements or material nonlinearity and damage, although in this study nonlinearity is not considered. Some fresh individuals after selection, crossover and mutation are inserted into population, and inserting new individuals can help to explore new candidates of the design points. Although some individuals with bad fitness can pass into the next generation, by inserting a new individual the average fitness of the current population will be better than the average of fitness of the previous population. As the optimum design, the best design points can be obtained in the final generation by copying the highest fitness value into the next generation. With the measure of the optimality defined by the fitness of individuals, GA does not need the gradient information to obtain the cost function. This condition makes GA suitable for use in hard and complex optimization problems, and it is capable of obtaining global optimum solutions in a simple way, although the problem of vibration control is generally a linear problem (Arfiadi 2000). To optimize the damper parameters for achieving the minimum response of an MDOF system, 
Table 2. Genetic algorithm (GA) parameters used in this study.

\begin{tabular}{lcc}
\hline GA parameters & Binary coding & Real coding \\
\hline Number of generations & 250 or 1000 & 1000 \\
Population & 30 & 20 \\
Probability of crossover & 0.5 & 0.8 \\
Probability of mutation & 0.01 & 0.01 \\
Number of new random chromosomes to be inserted after crossover and & 20 & 10 \\
$\quad$ mutation $(\%)$ & & \\
\hline
\end{tabular}

Table 3. Structural parameters of the two buildings in the numerical examples.

\begin{tabular}{|c|c|c|c|c|c|c|c|}
\hline & \multirow[b]{2}{*}{ Floors $(i)$} & \multicolumn{3}{|c|}{ Building A } & \multicolumn{3}{|c|}{ Building B } \\
\hline & & $m_{i}(\mathrm{t})$ & $\begin{array}{c}k_{i} \times 10^{5} \\
(\mathrm{kN} / \mathrm{m})\end{array}$ & $\begin{array}{c}c_{i} \times 10^{3} \\
(\mathrm{kN} \mathrm{sec} / \mathrm{m})\end{array}$ & $m_{i}(\mathrm{t})$ & $\begin{array}{c}k_{i} \times 10^{4} \\
(\mathrm{kN} / \mathrm{m})\end{array}$ & $\begin{array}{c}c_{i} \times 10^{3} \\
(\mathrm{kN} \mathrm{sec} / \mathrm{m})\end{array}$ \\
\hline \multirow[t]{6}{*}{ Examples 1 and 2} & 6 & 514 & 3.5 & 1.190 & 134 & 4.679 & 0.603 \\
\hline & 5 & 542 & 3.5 & 1.190 & 143 & 4.991 & 0.643 \\
\hline & 4 & 542 & 3.5 & 1.190 & 152 & 5.302 & 0.683 \\
\hline & 3 & 542 & 3.5 & 1.190 & 161 & 5.614 & 0.724 \\
\hline & 2 & 542 & 3.5 & 1.190 & 170 & 5.226 & 0.674 \\
\hline & 1 & 542 & 3.5 & 1.190 & 179 & 6.247 & 0.806 \\
\hline \multirow[t]{11}{*}{ Example 3} & 11 & 176 & 3.12 & 5.043 & - & - & - \\
\hline & 10 & 203 & 4.37 & 6.935 & 98 & 3.431 & 0.442 \\
\hline & 9 & 203 & 4.37 & 6.935 & 107 & 3.743 & 0.482 \\
\hline & 8 & 203 & 4.37 & 6.935 & 116 & 4.055 & 0.523 \\
\hline & 7 & 201 & 4.5 & 6.930 & 125 & 4.367 & 0.563 \\
\hline & 6 & 201 & 4.5 & 7.118 & 134 & 4.679 & 0.603 \\
\hline & 5 & 201 & 4.5 & 7.118 & 143 & 4.991 & 0.643 \\
\hline & 4 & 200 & 4.5 & 7.115 & 152 & 5.302 & 0.683 \\
\hline & 3 & 201 & 4.68 & 7.379 & 161 & 5.614 & 0.724 \\
\hline & 2 & 201 & 4.76 & 7.495 & 170 & 5.226 & 0.674 \\
\hline & 1 & 215 & 4.68 & 7.420 & 179 & 6.247 & 0.806 \\
\hline
\end{tabular}

extensive algorithms of dynamic response are required which also have to satisfy the limit of variables and other constraints. The variables used in the present study are of continuous type.

\subsection{Numerical Example 1}

In Example 1, a system of buildings located adjacent to each other and interconnected by passive dampers is considered to obtain the optimal passive damper parameters. Building A is a sixstorey shear building as discussed in Arfiadi and Hadi (2001, 2011), and Building B is a six-storey building as discussed in Sadek et al. (1997). The structures are considered as linear systems, similar to Pourzeynali, Lavasani, and Modarayi (2007), Pourzeynali and Zarif (2008), Shayeghi, Eimani Kalasar, and Shayeghi (2009) and Arfiadi and Hadi (2011). The adjacent buildings are Q1 subjected to the 1940 El Centro (117 El Centro Array-9 station) and the 1995 Kobe (KJMA station) excitations, where the maximum ground acceleration scaled to $0.3 \mathrm{~g}$ for $1940 \mathrm{El}$ Centro NS and $0.8 \mathrm{~g}$ for 1995 Kobe NS. The structural parameters of mass, stiffness and damping coefficient are shown for both buildings in Table 3. The damping matrix of Building A is assumed to be proportional to the stiffness matrix, corresponding to about $1.5 \%$ of the damping ratio of the first mode, while Building $\mathrm{B}$ has $2 \%$ of the damping ratio of the first mode.

The first objective of Example 1 is to determine the optimum value of stiffness $k_{d}$ and the damping coefficient $c_{d}$ of the dampers according to the performance index and regulated output. Note that the same damper parameters are used at each floor level. $H_{2}$ or $H_{\infty}$ norm transfer function is 
Table 4. Optimization results of Example 1.

\begin{tabular}{|c|c|c|c|c|c|c|c|c|c|c|}
\hline \multicolumn{11}{|c|}{ Building A } \\
\hline \multirow[b]{2}{*}{ Component } & \multicolumn{6}{|c|}{$H_{2}$ (binary code) } & \multicolumn{3}{|c|}{$H_{\infty}($ binary code $)$} & \multirow[b]{2}{*}{ Uncontrolled } \\
\hline & Case A & Case B & Case C & Case D & Case E & Case F & Case A & Case B & Case C & \\
\hline$c_{d}(\mathrm{kN} \mathrm{sec} / \mathrm{m})$ & 229.77 & 213.72 & 217.82 & 231.67 & 229.72 & 227.76 & 156.25 & 147.28 & 147.34 & - \\
\hline$k_{d}(\mathrm{kN} / \mathrm{m})$ & 312.43 & 394.66 & 495.24 & 324.59 & 314.46 & 328.13 & 977.47 & 1078.20 & 1139.40 & - \\
\hline$\omega_{1}(\mathrm{rad} / \mathrm{sec})$ & 4.98 & 5.03 & 5.09 & 4.99 & 4.98 & 4.99 & 5.33 & 5.37 & 5.40 & 6.29 \\
\hline$\omega_{2}(\mathrm{rad} / \mathrm{sec})$ & 6.35 & 6.36 & 6.38 & 6.35 & 6.35 & 6.35 & 6.52 & 6.55 & 6.57 & 18.51 \\
\hline$\omega_{3}(\mathrm{rad} / \mathrm{sec})$ & 13.24 & 13.26 & 13.28 & 13.24 & 13.24 & 13.24 & 13.40 & 13.42 & 13.43 & 29.65 \\
\hline$\omega_{4}(\mathrm{rad} / \mathrm{sec})$ & 39.07 & 39.07 & 39.08 & 39.07 & 39.07 & 39.07 & 39.09 & 39.09 & 39.09 & 39.06 \\
\hline$\omega_{5}(\mathrm{rad} / \mathrm{sec})$ & 46.22 & 46.22 & 46.22 & 46.22 & 46.22 & 46.22 & 46.23 & 46.23 & 46.24 & 46.21 \\
\hline$\omega_{6}(\mathrm{rad} / \mathrm{sec})$ & 50.68 & 50.68 & 50.68 & 50.68 & 50.68 & 50.68 & 50.69 & 50.69 & 50.70 & 50.67 \\
\hline$\xi_{1}(\%)$ & 17.38 & 15.84 & 15.41 & 17.42 & 17.36 & 17.15 & 9.44 & 8.57 & 8.29 & 1.07 \\
\hline$\xi_{2}(\%)$ & 5.61 & 5.57 & 6.02 & 5.69 & 5.61 & 5.62 & 6.38 & 6.09 & 6.27 & 3.15 \\
\hline$\xi_{3}(\%)$ & 13.99 & 13.57 & 13.63 & 14.03 & 13.98 & 13.93 & 12.17 & 11.77 & 11.75 & 5.04 \\
\hline$\xi_{4}(\%)$ & 7.21 & 7.17 & 7.19 & 7.22 & 7.21 & 7.21 & 7.05 & 7.01 & 7.01 & 6.64 \\
\hline$\xi_{5}(\%)$ & 8.34 & 8.31 & 8.32 & 8.34 & 8.34 & 8.34 & 8.20 & 8.17 & 8.17 & 7.86 \\
\hline$\xi_{6}(\%)$ & 9.06 & 9.02 & 9.03 & 9.06 & 9.06 & 9.05 & 8.93 & 8.90 & 8.90 & 8.61 \\
\hline
\end{tabular}

used, to be minimized with respect to different combinations of regulated outputs $\left(C_{w}\right)$. Several combinations of regulated output are used in this study, as follows. Case A: minimize displacements of both buildings; Case B: minimize displacements of the top floors of both buildings; Case C: minimize velocities of the top floors of the buildings; Case D: minimize absolute accelerations of the top floors of both buildings; Case E: minimize interstorey drifts of the buildings; and Case F: minimize interstorey drifts and displacements of top floors of the buildings. Table 4 shows the optimization results of the damper, damping and natural frequency of both buildings for all cases in $\mathrm{H}_{2}$ control and Cases $\mathrm{A}-\mathrm{C}$ in $H_{\infty}$ control. It can be noted that the optimization results of the passive damper from $\mathrm{H}_{\infty}$ control are larger than the results from $\mathrm{H}_{2}$ control. Case F, which minimizes interstorey drifts and displacements of the top floors of both buildings, is better than the other cases based on the obtained optimal results of natural frequency of both buildings. Table 5 shows the damper parameters for all cases when the different dampers are used in each floor level between the buildings. Case F obtains the optimal stiffness of damper compared with the other cases when different damper parameters are used in each storey. According to Equation (20), the details of several objectives with the regulated outputs used in this study are given in Table 6 . For each case, the GA is run four times. Figure 4 shows the evolving best fitness for Case A in $\mathrm{H}_{2}$ optimization. For the other cases the best fitness has the same form and is not shown here. It is important to highlight that the feedback control gain can be obtained. In this case, the study can conduct different combinations of the measurement as the feedback to obtain the appropriate controller, rather than choosing cases in real engineering control.

In Example 1, two design variables are chosen, i.e. stiffness $k_{d}$ and the damping coefficient $c_{d}$ when the same dampers are placed at all floor levels between the buildings. For binary coded GA- $H_{2}$ and $H_{\infty}$ optimization, the lower and upper bound values for each design variable are chosen. The number of independent variables involved in the objective function is subjected to explicit constraints with specific upper and lower limits of each constraint. The value of interstorey drift (implicit constraint) of limits of constraints is $0.1 \mathrm{~m}$. The lower and upper bound values of the stiffness (explicit constraint) are 0 and $4000 \mathrm{kN} / \mathrm{m}$, while the lower and upper bound values for the damping coefficient (explicit constraint) are 0 and $2000 \mathrm{kN} \mathrm{sec} / \mathrm{m}$, respectively. The length of the subchromosome (nbits) with three significant digits $\left(p_{i}\right)$ for the stiffness is taken as 22 , while the length of the subchromosome for the damping is taken as 20. Figure 5 shows the top floor displacement response of Building A under El Centro 1940 NS excitation. 
Table 5. Resulting damper parameters obtained by binary coded GA- $H_{\infty}$ optimization.

\begin{tabular}{llcccccc}
\hline Floors $(i)$ & Parameters & Case A & Case B & Case C & Case D & Case E & Case F \\
\hline 1 & $c_{d 1}(\mathrm{kN} \mathrm{sec} / \mathrm{m})$ & 922.38 & 16.369 & 137.38 & 1995 & 13.126 & 127.28 \\
& $k_{d 1}(\mathrm{kN} / \mathrm{m})$ & 2798.1 & 1606.7 & 3076.5 & 3620.5 & 3792.7 & 134.56 \\
2 & $c_{d 2}(\mathrm{kN} \mathrm{sec} / \mathrm{m})$ & 93.17 & 656.45 & 0.383 & 43.23 & 7.48 & 98.53 \\
& $k_{d 2}(\mathrm{kN} / \mathrm{m})$ & 2298.6 & 686.08 & 745.81 & 1990 & 2523.6 & 2934 \\
3 & $c_{d 3}(\mathrm{kN} \mathrm{sec} / \mathrm{m})$ & 55.49 & 17.031 & 50.97 & 14.99 & 43.15 & 38.35 \\
& $k_{d 3}(\mathrm{kN} / \mathrm{m})$ & 1742.4 & 578.11 & 1754.3 & 1617 & 1509.4 & 53.54 \\
4 & $c_{d 4}(\mathrm{kN} \mathrm{sec} / \mathrm{m})$ & 17.69 & 89.031 & 5.85 & 20.59 & 135.4 & 187.26 \\
& $k_{d 4}(\mathrm{kN} / \mathrm{m})$ & 785.32 & 251.77 & 188.98 & 369.01 & 435.69 & 296.06 \\
5 & $c_{d 5}(\mathrm{kN} \mathrm{sec} / \mathrm{m})$ & 0.07 & 9.96 & 202.97 & 163.13 & 248.14 & 64.60 \\
& $k_{d 5}(\mathrm{kN} / \mathrm{m})$ & 17.17 & 368.55 & 643.67 & 964.72 & 998.08 & 309 \\
6 & $c_{d 6}(\mathrm{kN} \mathrm{sec} / \mathrm{m})$ & 349.13 & 234.36 & 217.61 & 156.05 & 109.51 & 216.57 \\
& $k_{d 6}(\mathrm{kN} / \mathrm{m})$ & 1072.6 & 1998 & 1500 & 994.83 & 481.8 & 1891.8 \\
\hline
\end{tabular}

Table 6. Objectives with the corresponding regulated outputs.

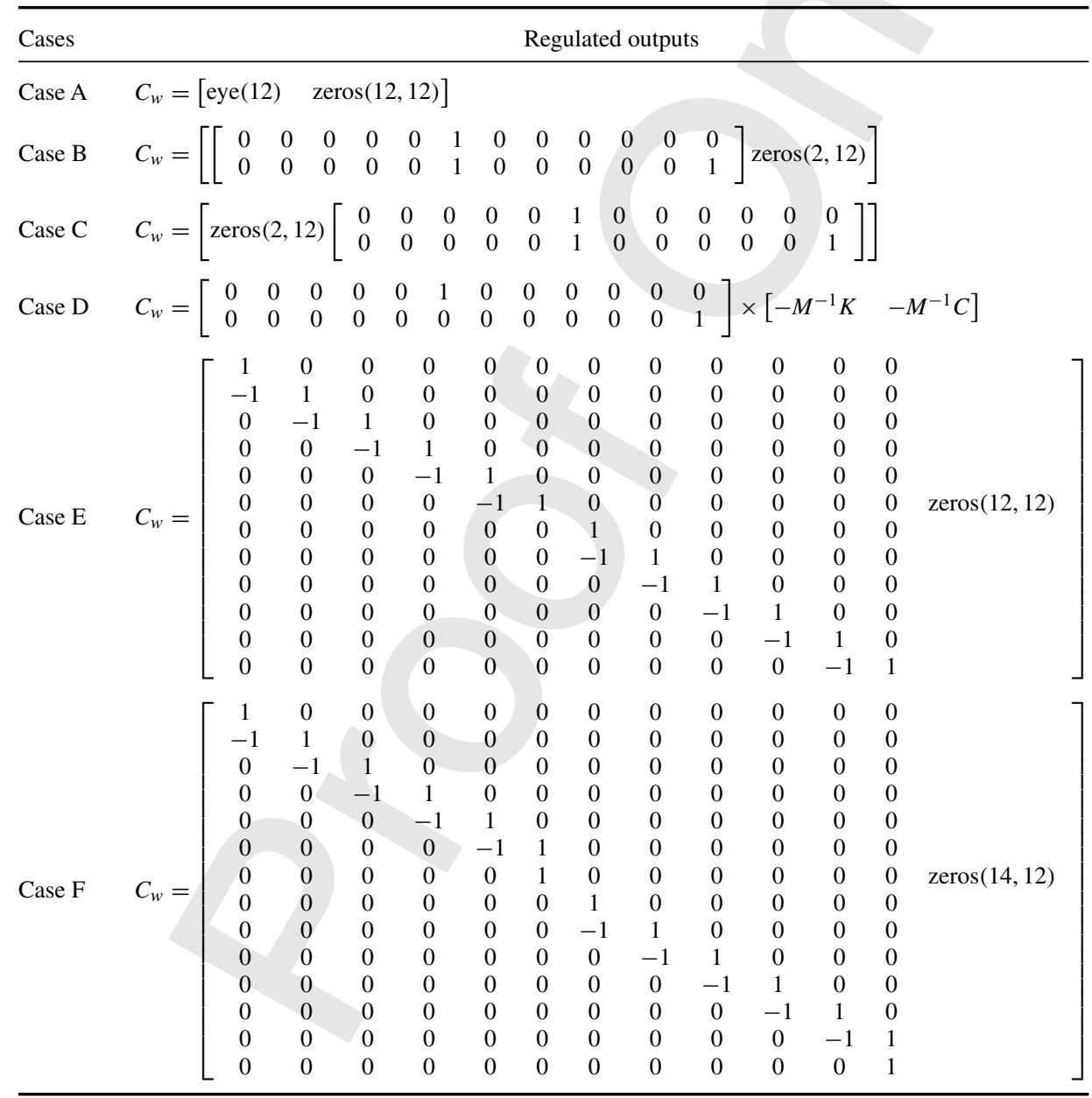

The reduction in displacement of about $25 \%$ for Case A between buildings with and without control is shown in Figure 5. Using dampers between the buildings is effective in reducing the response. Figure 6 shows a comparison between the optimized buildings using several regulated 


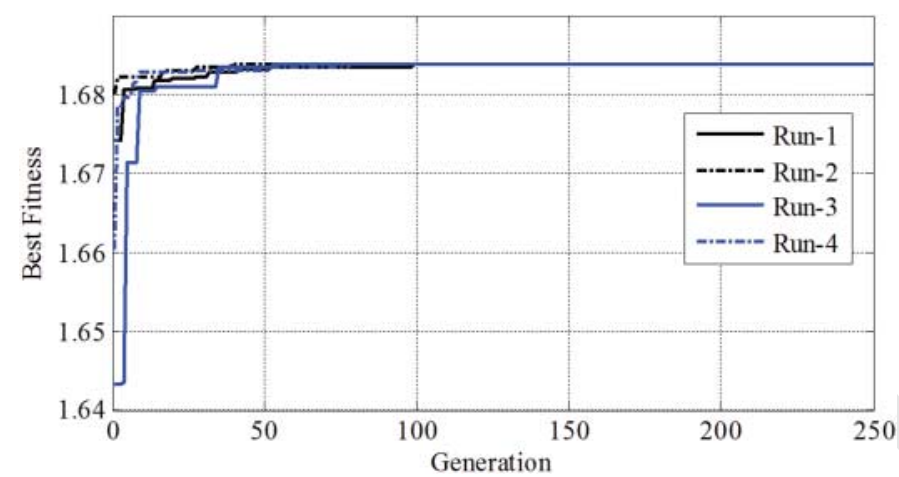

Figure 4. Evolving best fitness for Case A with binary coded GA- $\mathrm{H}_{2}$ optimization.

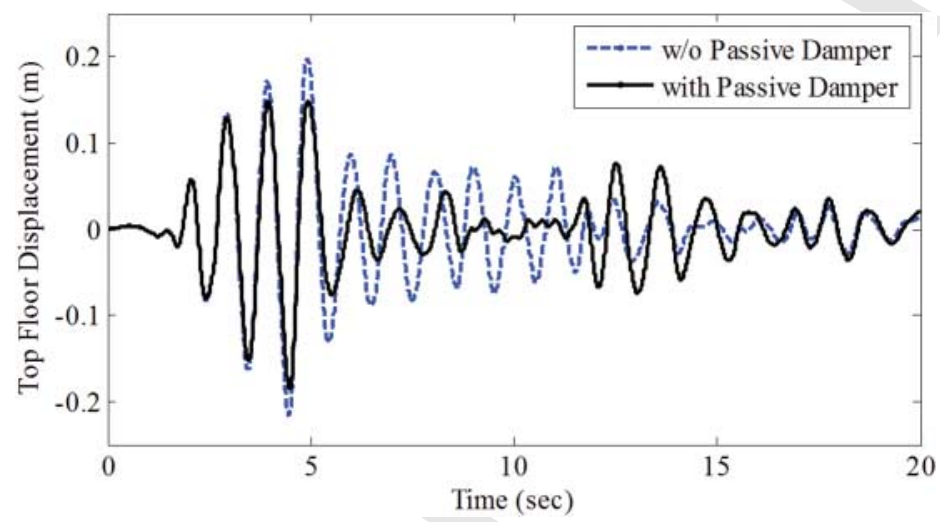

Figure 5. Displacement response of the top floor of Building A for Case A with $\mathrm{H}_{2}$ optimization under El Centro 1940 NS excitation.

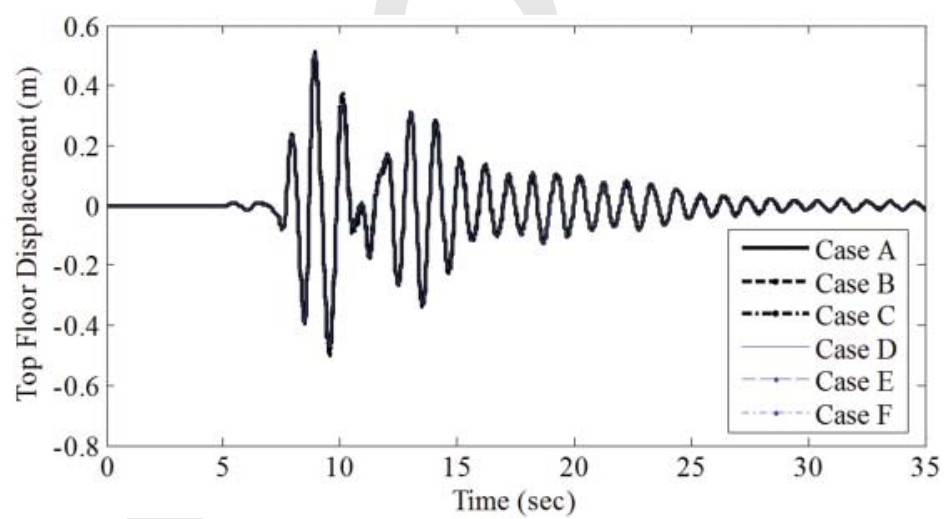

Figure 6. Displacement response of the top floor of Building B for all cases with $\mathrm{H}_{2}$ optimization under Kobe 1995 NS excitation.

outputs. The reduction in the response is similar in all chosen regulated outputs using the optimized parameters from either $H_{2}$ or $H_{\infty}$ controls. The damper force is normalized with the weight of Building A in Figure 7. It can be seen from Figure 7 that there is significant energy dissipation in the passive case. 

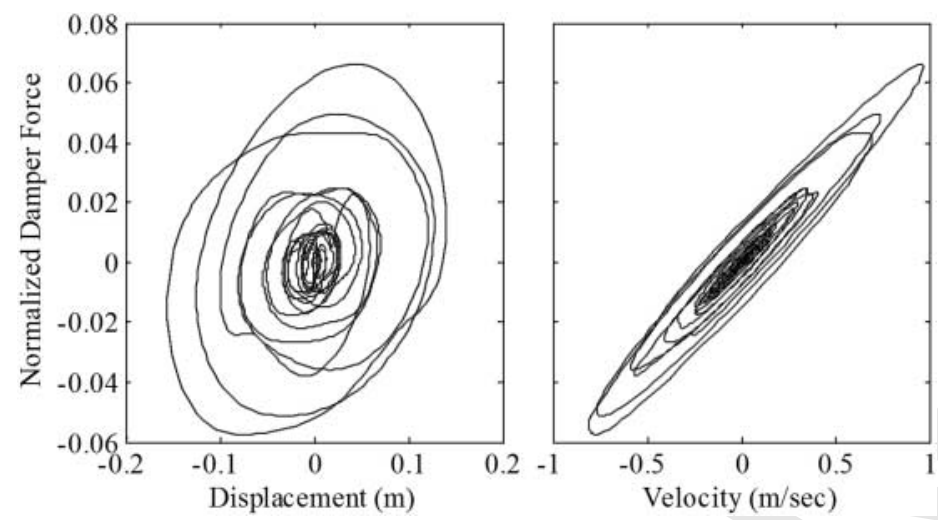

Figure 7. Behaviour of viscoelastic damper under El Centro 1940 NS excitation.

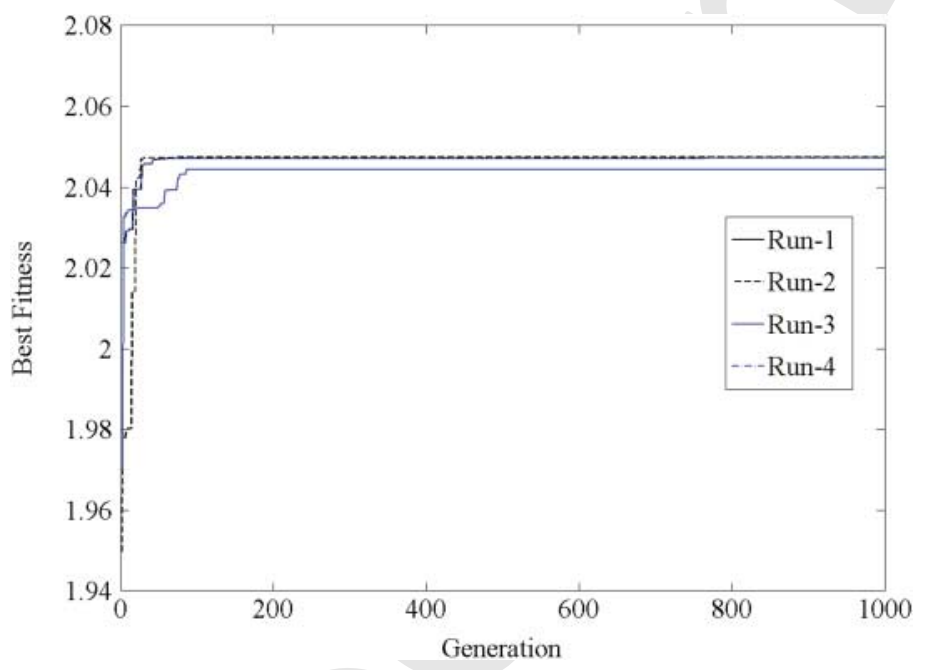

Figure 8. Evolving best fitness for Case F with binary coded GA- $H_{\infty}$ optimization.

\subsection{Numerical Example 2}

In Example 2, adjacent buildings with the same structural parameters as in Example 1 are used, except that each floor is connected with a damper. Here, the top floors of the adjacent buildings are connected with the active damper system to increase the capability of the passive viscoelastic damper. Furthermore, adjacent buildings are then subjected to El Centro and Kobe excitations as in Example 1, but the maximum ground acceleration is scaled to $0.1 \mathrm{~g}$ and $0.3 \mathrm{~g}$ for both excitations. If the active control force is placed between the adjacent buildings at the top floor level, the damper is now serving as a viscoelastic damper with an actuator. A viscoelastic damper is placed at the top floor level between the buildings with $c_{d}=515.63 \mathrm{kN} \mathrm{sec} / \mathrm{m}$ and $k_{d}=3101 \mathrm{kN} / \mathrm{m}$.

The parametric values of the viscoelastic damper are optimized using the binary coding GA$H_{\infty}$ norm with Case $\mathrm{F}$ as in the method in Example 1. Figure 8 shows the evolving best fitness for Case $\mathrm{F}$ in $H_{\infty}$ optimization. In Example 2, the controller gains are obtained using real coded 


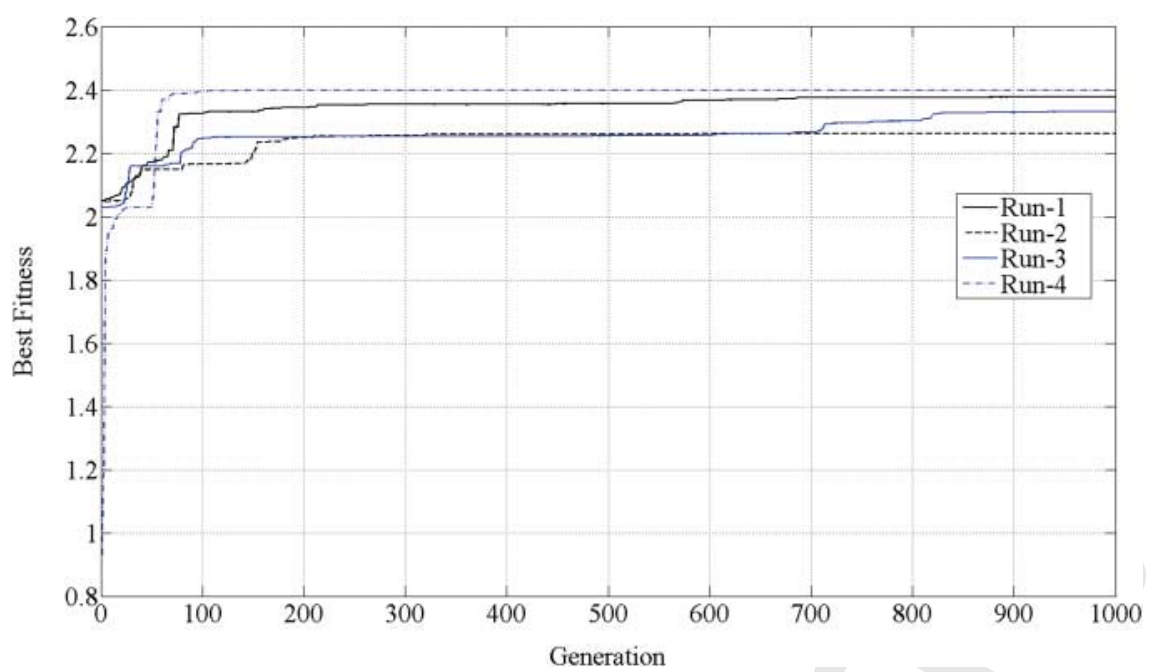

Figure 9. Evolving best fitness for the gains of Example 2 Case $\mathrm{F}$ with real coded GA- $H_{\infty}$ optimization.

(a)

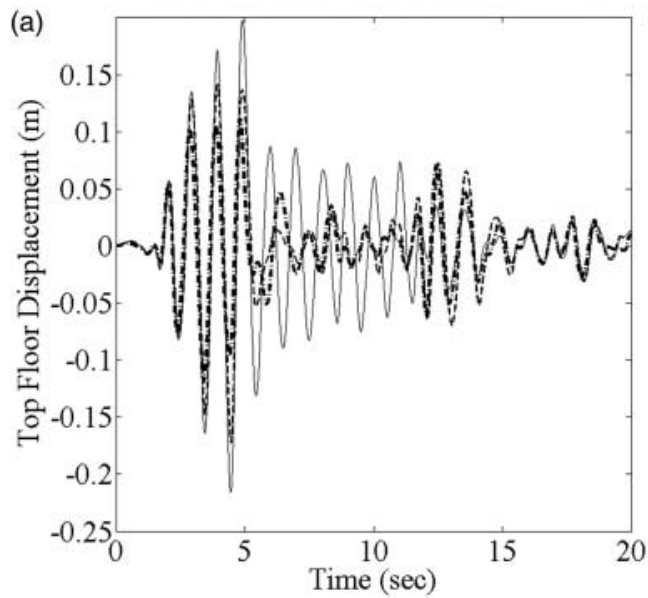

(b)

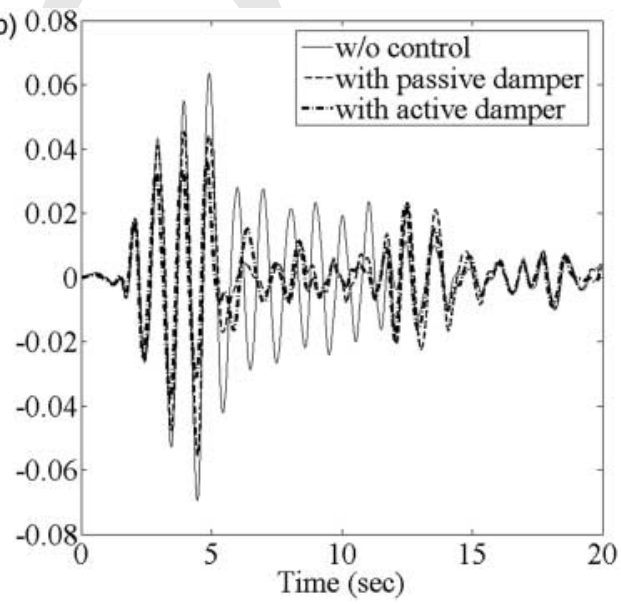

Figure 10. Top floor displacement of Building A with uncontrolled, passive control and active control system due to El Centro NS 1940 excitation: (a) $0.3 \mathrm{~g}$; (b) $0.1 \mathrm{~g}$.

GA with the performance index $H_{\infty}$ norm. One actuator and four gains are used in Example 2 . Hence, four design variables are to be determined as shown in Appendix 1. As in Example 1, four runs have been conducted by changing the initial value of the upper and lower bounds of the controller gain in each run. Hence, different values are conducted to explore the unknown domain of the gain and to compare the robustness of the algorithm with the initial value. The first four runs of the lower bound are chosen as $-10,-10,0$ and -1000 , while the first four runs of the upper bound are 10,-1,100 and 100 .

Figure 9 shows the evolving best fitness for Example 2 Case F, with interstorey drifts and the top floor displacement of both buildings as the feedback and $H_{\infty}$ norm as the objective function.

Figures 10 and 11 show the response of the top floor of Building A Case F subject to El Centro NS and Kobe NS excitations with maximum ground acceleration of $0.3 \mathrm{~g}$ and $0.1 \mathrm{~g}$, respectively. 
(a)

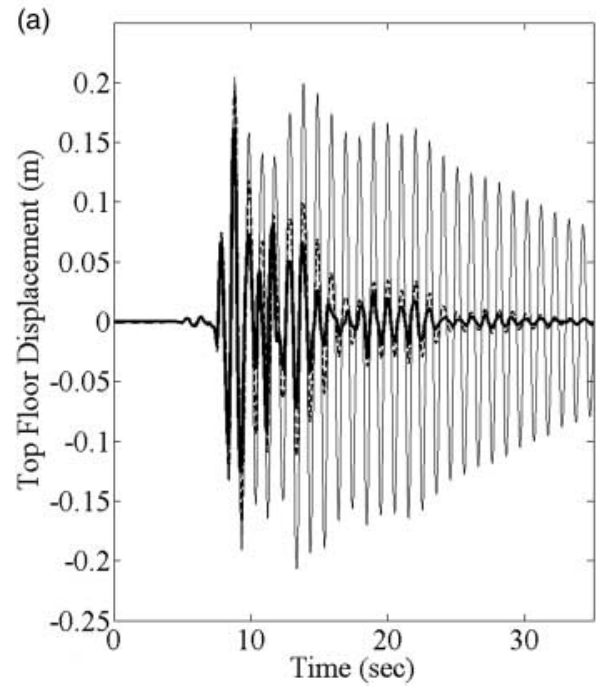

(b)

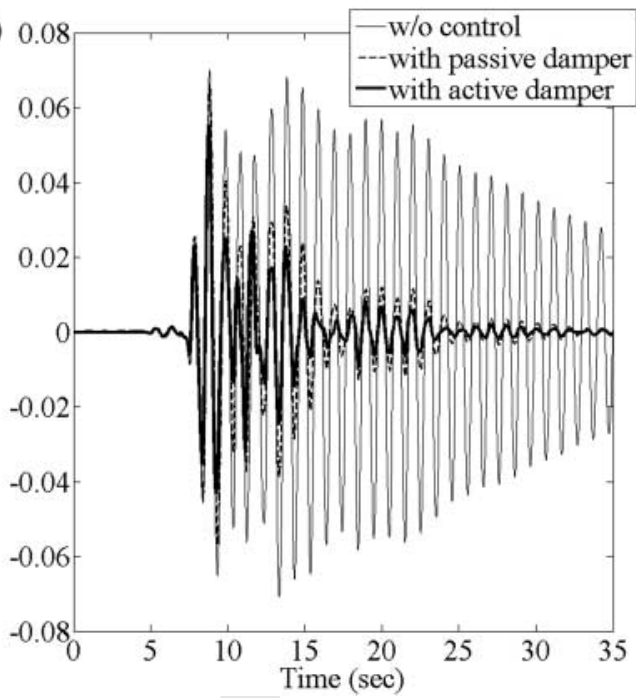

Figure 11. Top floor displacement of Building A with uncontrolled, passive control and active control system due to Kobe 1995 NS excitation: (a) $0.3 \mathrm{~g}$; (b) $0.1 \mathrm{~g}$.

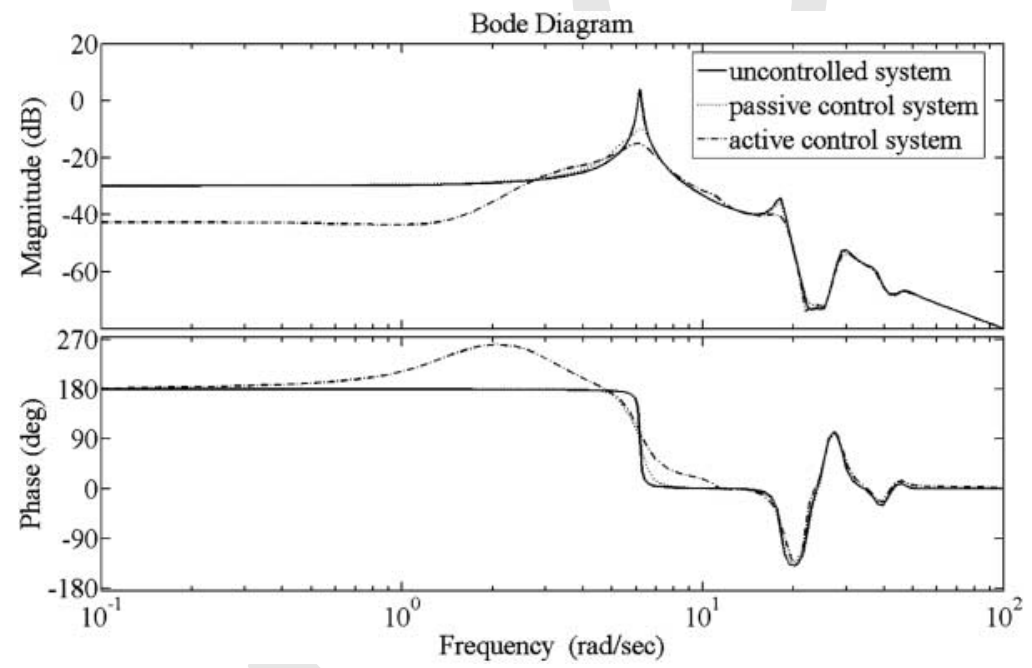

Figure 12. Transfer function in Example 2 from external excitation to the top floor displacement of Building A.

It can be seen from Figures 10 and 11 that the response is slightly reduced by using an active system, where the maximum control forces are $u_{\max }=2021 \mathrm{kN}$ and $u_{\max }=649 \mathrm{kN}$ for El Centro earthquake with $0.3 \mathrm{~g}$ and $0.1 \mathrm{~g}$, and $u_{\max }=2107.5 \mathrm{kN}$ and $u_{\max }=721 \mathrm{kN}$ for Kobe earthquake with $0.3 \mathrm{~g}$ and $0.1 \mathrm{~g}$, respectively. Figure 12 shows the transfer function from the external disturbance to the top floor of Building A. The effect of linking buildings with either passive or active control systems compared with an uncontrolled system can be observed from the peak magnitude in the Bode diagram. The designed adjacent buildings with dampers provide a reduction in the response of each building around the frequency of the first mode, where the highest contribution to the response of each building is as shown in Figure 12. 
Table 7. Maximum displacements with respect to ground, El Centro 1940 earthquake (Building B).

\begin{tabular}{|c|c|c|c|c|c|c|c|c|c|c|c|c|c|c|}
\hline \multirow[b]{2}{*}{ Floor } & \multicolumn{2}{|c|}{$\begin{array}{l}\text { Maximum uncontrolled } \\
\text { response }(\mathrm{m})\end{array}$} & \multicolumn{2}{|c|}{$\begin{array}{c}\text { Den Hartog (1947) } \\
\text { TMD }\end{array}$} & \multicolumn{2}{|c|}{$\begin{array}{l}\text { Warburton (1982) } \\
\text { TMD }\end{array}$} & \multicolumn{2}{|c|}{$\begin{array}{c}\text { Sadek et al.(1997) } \\
\text { TMD }\end{array}$} & \multicolumn{2}{|c|}{$\begin{array}{l}\text { Hadi and Arfiadi (1998) } \\
\text { GA }\end{array}$} & \multicolumn{2}{|c|}{$\begin{array}{c}\text { Bekdas and Nigdeli (2011) } \\
\text { HS }\end{array}$} & \multicolumn{2}{|c|}{$\begin{array}{l}\text { Present approach } \\
\text { GA }-H_{\infty}\end{array}$} \\
\hline & $x(m)$ & $x / \sec ^{2}$ & $x(m)$ & $x / \sec ^{2}$ & $x(m)$ & $x / \sec ^{2}$ & $x(m)$ & $x / \sec ^{2}$ & $x(m)$ & $x / \sec ^{2}$ & $x(m)$ & $x / \sec ^{2}$ & $x(m)$ & $x / \sec ^{2}$ \\
\hline 1 & 0.041 & 3.056 & 0.034 & 3.049 & 0.036 & 3.077 & 0.036 & 3.060 & 0.034 & 3.048 & 0.027 & - & 0.017 & 2.842 \\
\hline 2 & 0.088 & 2.766 & 0.074 & 2.636 & 0.079 & 2.695 & 0.077 & 2.659 & 0.072 & 2.632 & 0.058 & - & 0.037 & 2.556 \\
\hline 3 & 0.129 & 2.977 & 0.106 & 2.764 & 0.114 & 2.750 & 0.113 & 2.713 & 0.105 & 2.778 & 0.083 & - & 0.054 & 2.469 \\
\hline 4 & 0.166 & 2.755 & 0.136 & 2.707 & 0.147 & 2.727 & 0.145 & 2.717 & 0.134 & 2.704 & 0.105 & - & 0.068 & 2.782 \\
\hline 5 & 0.197 & 2.933 & 0.163 & 2.678 & 0.177 & 2.671 & 0.172 & 2.693 & 0.160 & 2.673 & 0.124 & - & 0.081 & 3.146 \\
\hline 6 & 0.222 & 3.136 & 0.187 & 2.878 & 0.206 & 2.921 & 0.194 & 2.953 & 0.184 & 2.853 & 0.140 & - & 0.090 & 3.286 \\
\hline 7 & 0.252 & 2.922 & 0.213 & 2.365 & 0.236 & 2.426 & 0.219 & 2.454 & 0.210 & 2.336 & 0.157 & - & 0.099 & 2.813 \\
\hline 8 & 0.286 & 3.675 & 0.239 & 2.711 & 0.267 & 2.913 & 0.245 & 2.713 & 0.236 & 2.696 & 0.177 & - & 0.107 & 3.619 \\
\hline 9 & 0.313 & 4.697 & 0.261 & 3.222 & 0.292 & 3.443 & 0.266 & 3.251 & 0.258 & 3.199 & 0.195 & - & 0.112 & 4.677 \\
\hline 10 & 0.327 & 5.363 & 0.276 & 3.876 & 0.310 & 4.129 & 0.281 & 3.898 & 0.272 & 3.855 & 0.205 & - & 0.114 & 5.355 \\
\hline
\end{tabular}

Note: $\mathrm{TMD}=$ tuned mass damper; $\mathrm{GA}=$ genetic algorithm; $\mathrm{HS}=$ harmony search. 
Table 8. Comparison of the effectiveness of the different controllers used in this study under the El Centro 1940 earthquake.

\begin{tabular}{|c|c|c|c|c|c|c|c|}
\hline \multirow[b]{4}{*}{ Floor } & \multirow{4}{*}{$\begin{array}{l}\text { Maximum } \\
\text { uncontrolled } \\
\text { response } \\
x(m)\end{array}$} & \multicolumn{6}{|c|}{ Controlled to uncontrolled response ratio (reduction ratio) } \\
\hline & & \multicolumn{3}{|c|}{ Pourzeynaliet al. (2006) } & \multicolumn{3}{|c|}{ Present approach } \\
\hline & & \multirow{2}{*}{$\begin{array}{c}\text { Passive } \\
\text { TMD }\end{array}$} & \multicolumn{2}{|c|}{ Active } & \multirow{2}{*}{$\begin{array}{c}\text { Passive } \\
H_{\infty}-\mathrm{GA}\end{array}$} & \multicolumn{2}{|c|}{ Active } \\
\hline & & & LQR & GFLC & & & R-GA \\
\hline 1 & 0.019 & 0.68 & 0.49 & 0.45 & 0.67 & 0.56 & 0.55 \\
\hline 2 & 0.039 & 0.64 & 0.46 & 0.40 & 0.68 & 0.56 & 0.55 \\
\hline 3 & 0.057 & 0.65 & 0.47 & 0.40 & 0.69 & 0.57 & 0.54 \\
\hline 4 & 0.074 & 0.65 & 0.47 & 0.38 & 0.69 & 0.57 & 0.54 \\
\hline 5 & 0.09 & 0.64 & 0.48 & 0.38 & 0.69 & 0.58 & 0.52 \\
\hline 6 & 0.10 & 0.67 & 0.50 & 0.39 & 0.69 & 0.58 & 0.50 \\
\hline 7 & 0.12 & 0.62 & 0.48 & 0.36 & 0.68 & 0.59 & 0.46 \\
\hline 8 & 0.13 & 0.64 & 0.46 & 0.36 & 0.68 & 0.59 & 0.42 \\
\hline 9 & 0.14 & 0.67 & 0.48 & 0.35 & 0.67 & 0.59 & 0.38 \\
\hline 10 & 0.14 & 0.67 & 0.50 & 0.36 & 0.66 & 0.60 & 0.34 \\
\hline 11 & 0.147 & 0.673 & 0.49 & 0.35 & 0.66 & 0.61 & 0.29 \\
\hline
\end{tabular}

Note: $\mathrm{TMD}=$ tuned mass damper; $\mathrm{LQR}=$ linear quadratic regulator; GFLC $=$ genetic fuzzy logic controller; $\mathrm{GA}=$ genetic algorithm.

Table 9. Comparison of the effectiveness of the approach used in this study under the Kobe 1995 earthquake.

\begin{tabular}{|c|c|c|c|c|c|}
\hline \multirow[b]{4}{*}{ Floor } & & & \multicolumn{3}{|c|}{ Controlled to uncontrolled response ratio (reduction ratio) } \\
\hline & & & Pourzeyna & al. (2006) & Present approach \\
\hline & \multicolumn{2}{|c|}{ Maximum uncontrolled response $x(m)$} & \multicolumn{2}{|c|}{ Passive (TMD) } & Passive (GA) \\
\hline & Building A & Building B & Building A & Buil & Building B \\
\hline 1 & 0.06 & 0.09 & 0.82 & $\theta .81$ & 0.55 \\
\hline 2 & 0.12 & 0.18 & 0.82 & $\theta .81$ & 0.54 \\
\hline 3 & 0.18 & 0.26 & 0.83 & 0.82 & 0.54 \\
\hline 4 & 0.24 & 0.33 & 0.83 & $\theta .82$ & 0.55 \\
\hline 5 & 0.29 & 0.38 & 0.82 & 0.83 & 0.58 \\
\hline 6 & 0.34 & 0.43 & 0.85 & 0.83 & 0.62 \\
\hline 7 & 0.39 & 0.48 & 0.85 & 0.83 & 0.64 \\
\hline 8 & 0.43 & 0.51 & 0.84 & $\theta .84$ & 0.64 \\
\hline 9 & 0.46 & 0.55 & 0.85 & $\theta .84$ & 0.63 \\
\hline 10 & 0.48 & 0.57 & 0.85 & $\theta .83$ & 0.62 \\
\hline 11 & 0.50 & - & 0.84 & 0.83 & - \\
\hline
\end{tabular}

Note: $\mathrm{TMD}=$ tuned mass damper.

\subsection{Numerical Example 3}

For the real engineering cases, an 11-storey realistic building, located in the city of Rasht, Iran, as discussed by Pourzeynali, Lavasani, and Modarayi (2007) and a 10-storey building, as discussed by Arfiadi (2000) and Sadek et al. (1997) are taken as Building A and Building B, respectively, as shown in Table 3. The structures are also considered as linear systems. Coefficients for the passive system and controller gains for the active system are obtained successfully with the same program. To check the accuracy of the mechanical model of the damped structure, the proposed approach is compared with several optimization methods developed by Hadi and Arfadi (2011) (GA), Q2 and Sadek et al. (1997), Warburton (1982), Den Hartog (1947) and Bekdas and Nigdeli (2011) (HS), as shown in Table 7. It is found that the maximum top storey displacement of Building B Q3 
(Case F) is reduced, with a reduction of 65.14\% under El Centro (1940) NS excitation, while other methods showed less reduction: Bekdas and Nigdeli (2011) (HS): 37.31\%; Den Hartog (1947): 15.60\%; Warburton: 5.2\%; Sadek et al. (1997): 14.07\%; and Hadi and Arfiadi (1998) (GA): $16.82 \%$. The results of the controlled displacement response of the top storey of Building A in Case F, determined by TMD and LQR systems, are compared with the corresponding uncontrolled ones under El Centro earthquake. Here, TMD and LQR systems were used for only the example building (Building A) in the study of Pourzeynali, Lavasani, and Modarayi (2007). As shown in Table 8, the maximum displacement of the top floor of the 11-storey building is reduced, with a response reduction of $32.7 \%$ and $51 \%$ for TMD and LQR, while the reduction ratios of the proposed approach are 34\% (passive system), 39\% (GA- $\left.H_{\infty}\right)$ and $71 \%$ (LQR-GA). Table 9 shows the effectiveness of these control systems in reducing the response of Example 3 under Kobe 1995 excitation. It is also noted from Table 9 that since the PGA of the Kobe earthquake is about $0.8178 \mathrm{~g}$, Kobe excitation causes the maximum displacement (about $0.5 \mathrm{~m}$ ) in the top floor of the example building.

\section{Conclusions}

To enhance the seismic performance of adjacent buildings, the optimal analysis of both passive and active control systems has been investigated in this study. Control algorithms based on modern control theory have been used to optimize damper parameters for passive control systems and active controller gains for active control systems. The study can be divided into two sections. First, binary and real coded GAs using $\mathrm{H}_{2}$ and $H_{\infty}$ performance indices have been used to optimize the damper parameters in the passive control system. The individual with the best fitness is copied to the next generation using an elitist strategy. The results of Example 1 show that the viscoelastic damper is quite effective, with a reduction of about $25 \%$ in the response of both adjacent buildings.

Secondly, to enhance the damper effectiveness, the real coded GA used in this study helps to obtain the optimum controller gains in the response of adjacent buildings coupled by active control systems on the top floor in an efficient manner, as shown in Example 2. A static output feedback controller, where the gain is multiplied directly by the measurement output without an observer, is used as feedback control. This makes the system framework simpler than a dynamic output controller. In Example 3, by comparison with other studies in the literature, the proposed method is appropriate based on reducing displacement and acceleration responses during an earthquake rather than using dampers for each individual building. On the other hand, active dampers between buildings use larger control forces than dampers used for individual buildings. As a result, Example 2, of two adjacent six-storey buildings coupled by either passive or active dampers at the top floor level, demonstrates that the controlled design approach can systematically achieve enhanced seismic performance with economical efficiency, rather than using dampers on all storeys.

\section{References}

Ahlawat, A. S., and A. Ramaswamy. 2003. "Multiobjective Optimal Absorber System for Torsionally Coupled Seismically Excited Structures." Engineering Structures 25: 941-950.

Aldemir, U. 2010. "A Simple Active Control Algorithm for Earthquake Excited Structures." Computer-Aided Civil and Infrastructure Engineering 25 (3): 218-225.

Arfiadi, Y. 2000. "Optimal Passive and Active Control Mechanisms for Seismically Excited Buildings.” PhD thesis, Faculty of Engineering, University of Wollongong, Wollongong.

Arfiadi, Y., and M. N. S. Hadi. 2000. "Passive and Active Control of Three-Dimensional Buildings." Earthquake Engineering \& Structural Dynamics 29 (3): 377-396. 
Arfiadi, Y., and M. N. S. Hadi. 2001. "Optimal Direct (Static) Output Feedback Controller Using Real Coded Genetic Algorithms." Computers \& Structures 79 (17): 1625-1634.

Arfiadi, Y., and M. N. S. Hadi. 2006. "Continuous Bounded Controllers for Active Control of Structures." Computers \& Structures 84 (12): 798-807.

Arfiadi, Y. and M. N. S. Hadi. 2011. "Optimum Placement and Properties of Tuned Mass Dampers Using Hybrid Genetic Algorithms." International Journal of Optimization in Civil Engineering 1: 167-187.

Bekdas, G., and S. M. Nigdeli. 2011. "Estimating Optimum Parameters of Tuned Mass Dampers Using Harmony Search." Engineering Structures 33 (9): 2716-2723.

Bekdas, G., and S. M. Nigdeli. 2013. "Response of Discussion 'Estimating Optimum Parameters of Tuned Mass Dampers Using Harmony Search'.” Engineering Structures 54 (0): 265-267.

Bharti, S. D., S. M. Dumne, and M. K. Shrimali. 2010. "Seismic Response Analysis of Adjacent Buildings Connected with MR Dampers." Engineering Structures 32 (8): 2122-2133.

Christenson, R. E., J. B. F. Spencer, N. Hori, and K. Seto. 2003. "Coupled Building Control Using Acceleration Feedback." Computer-Aided Civil and Infrastructure Engineering 18 (1): 4-18.

Den Hartog, J. P. 1947. Mechanical Vibrations. New York: McGraw-Hill Book Company.

Dyke, S. J., et al. 1996. “Acceleration Feedback Control of MDOF Structures.” Journal of Engineering Mechanics 122 (9): 907-918.

Fadel Miguel, L. F., R. H. Lopez, and L. F. F. Miguel. 2013. "Discussion of Article: 'Estimating Optimum Parameters of Tuned Mass Dampers Using Harmony Search' [Eng. Struct. 33 (9) (2011) 2716-2723].” Engineering Structures 54 (0): 262-264

Gholizadeh, S. 2013. "Layout optimization of truss structures by hybridizing cellular automata and particle swarm optimization." Computers \& Structures 125 (0): 86-99.

Gholizadeh, S. and A. Barzegar. 2012. "Shape Optimization of Structures for Frequency Constraints by Sequential Harmony Search Algorithm.” Engineering Optimization 45 (6): 627-646.

Goldberg, D. E. 1989. Genetic Algorithms in Search, Optimization and Machine Learning. Reading, MA: Addison-Wesley.

Hadi, M. N. S., and Y. Arfiadi. 1998. "Optimum Design of Absorber for MDOF Structures." Journal of Structural Engineering 124 (11): 1272-1280.

Herrera, F., M. Lozano, and J. L. Verdegay. 1998. "Tackling Real-Coded Genetic Algorithms: Operators and Tools for Behavioural Analysis.” Artificial Intelligence Review 12 (4): 265-319.

Holland, J. H. 1992. Adaptation in Natural and Artificial Systems. Cambridge, MA: MIT Press.

Kim, J., J. Ryu, and L. Chung. 2006. "Seismic Performance of Structures Connected by Viscoelastic Dampers." Engineering Structures 28 (2): 183-195.

Lee, C.-L., Y.-T. Chen, L.-L. Chung, and Y.-P. Wang. 2006. "Optimal Design Theories and Applications of Tuned Mass Dampers." Engineering Structures 28 (1): 43-53.

Leung, A. Y. T., and H. Zhang. 2009. "Particle Swarm Optimization of Tuned Mass Dampers." Engineering Structures 31 (3): 715-728.

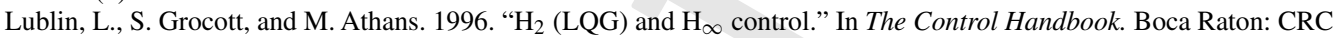
Press, pp. 635-650.

Michalewicz, Z. 1996. Genetic Algorithms + Data Structures = Evolution Programs. Berlin: Springer.

Ni, Y. Q., J. M. Ko, and Z. G. Ying. 2001. "Random Seismic Response Analysis of Adjacent Buildings Coupled with Non-Linear Hysteretic Dampers." Journal of Sound and Vibration 246 (3): 403-417.

Ok, S.-Y., J. Song, and K.-S. Park. 2009. "Development of Optimal Design Formula for Bi-Tuned Mass Dampers Using Multi-Objective Optimization." Journal of Sound and Vibration 322 (1-2): 60-77.

Pourzeynali, S., H. H. Lavasani, and A. H. Modarayi. 2007. "Active Control of High Rise Building Structures Using Fuzzy Logic and Genetic Algorithms." Engineering Structures 29 (3): 346-357.

Pourzeynali, S., and M. Zarif. 2008. "Multi-Objective Optimization of Seismically Isolated High-Rise Building Structures Using Genetic Algorithms.” Journal of Sound and Vibration 311 (3-5): 1141-1160.

Sadek, F., B. Mohraz, A. W. Taylor, and R. M. Chung. 1997. "A Method of Estimating the Parameters of Tuned Mass Dampers for Seismic Applications.” Earthquake Engineering \& Structural Dynamics 26 (6): 617-635.

Shayeghi, A., H. Eimani Kalasar, and H. Shayeghi. 2009. "Seismic Control of Tall Building Using a New Optimum Controller Based on GA.” World Academy of Science, Engineering and Technology 57: 702-709.

Spencer, B. F., Jr., and M. K. Sain. 1997. "Controlling Buildings: A New Frontier in Feedback." Control Systems, IEEE 17 (6): 19-35.

Spencer, J. B. F., J. Suhardjo, and M. K. Sain. 1994. "Frequency Domain Optimal Control Strategies for Aseismic Protection." Journal of Engineering Mechanics 120 (1): 135-158.

Warburton, G. B. 1982. "Optimal Absorber Parameters for Various Combination of Response and Excitation Parameters." Earthquake Engineering and Structural Dynamics 10: 381-401.

Westermo, B. 1989. "The Dynamics of Interstructural Connection to Prevent Pounding." Earthquake Engineering and Structural Dynamics 18: 687-699.

Xu, Y. L., Q. He, and J. M. Ko. 1999. “Dynamic Response of Damper-Connected Adjacent Buildings Under Earthquake Excitation." Engineering Structures 21 (2): 135-148.

Yang, Z., Y. L. Xu, and X. L. Lu. 2003. "Experimental Seismic Study of Adjacent Buildings with Fluid Dampers." Journal of Structural Engineering 129 (2): 197-205.

Yoshida, O., and S. J. Dyke. 2004. "Seismic Control of a Nonlinear Benchmark Building Using Smart Dampers." Journal of Engineering Mechanics 130 (4): 386-392. 
Zhu, H., Y. Wen, and H. Iemura. 2001. "A Study on Interaction Control for Seismic Response of Parallel Structures." Computers \& Structures 79 (2): 231-242.

\section{Appendix 1. Matrices in equation of motion}

If the state vector $X$ in Equation (5) is taken as the relative displacement and velocity with respect to the ground, the required matrices in the equation of motion are as follows:

$$
\begin{aligned}
& M_{1}=\operatorname{diag}\left[m_{1} \quad m_{2} \quad \ldots \quad m_{i} \quad m_{n}\right], \quad M_{2}=\operatorname{diag}\left[\begin{array}{llllll}
m_{1} & m_{2} & \ldots & m_{j} & m_{m}
\end{array}\right] \\
& C_{1}=\left[\begin{array}{ccccc}
\left(c_{1}+c_{2}\right) & -c_{2} & & & \\
-c_{2} & \left(c_{2}+c_{3}\right) & -c_{3} & & \\
& \vdots & \vdots & & \\
& & & -c_{n-1} & c_{n}
\end{array}\right], \quad c_{d(m, m)}=\operatorname{diag}\left[\begin{array}{llll}
c_{d 1} & c_{d 2} & \ldots & c_{d m}
\end{array}\right]
\end{aligned}
$$

$C_{2}$ is the $(m \times m)$ damping matrix of $m$ storey Building $\mathrm{B}$, which is similar to the $C_{1}$ damping matrix. The stiffness matrices of both buildings can be written as the damping matrices by replacing $c_{i}$ with $k_{i}$. Here, $i$ denotes the $i$ th storey.

$$
K_{2}=\left[\begin{array}{ccccc}
\left(k_{1}+k_{2}\right) & -k_{2} & & & \\
-k_{2} & \left(k_{2}+k_{3}\right) & -k_{3} & & \\
& \vdots & \vdots & & \\
& & & & -k_{m-1} \\
& & & -k_{m-1} & k_{m}
\end{array}\right], k_{d(m, m)}=\operatorname{diag}\left[k_{d 1} \quad k_{d 2} \quad \cdots \quad k_{d m}\right]
$$

For the numerical Example 2, the other matrices in Equation (6) are

$$
\begin{aligned}
& \mathrm{P}_{1}=\left[\begin{array}{llllll}
0 & 0 & 0 & 0 & 0 & -1
\end{array}\right]^{T} \\
& \mathrm{P}_{2}=\left[\begin{array}{llllll}
0 & 0 & 0 & 0 & 0 & 1
\end{array}\right]^{T}
\end{aligned}
$$

where $P_{1}$ and $P_{2}$ are $m \times n_{a}$-dimensional matrices based on the number of actuators of the additional dampers and placement of dampers in the storey. $m$ denotes the storey number of the lower building. $X_{1}=\left[\begin{array}{lllll}x_{1} & x_{2} & \cdots & x_{n-1} & x_{n}\end{array}\right]$ contains $x_{i}$ displacement of the $i$ th floor of Building A relative to ground $(i=1,2, \ldots, n)$, while $X_{2}=$ $\left[\begin{array}{lllll}x_{1} & x_{2} & \ldots & x_{m-1} & x_{m}\end{array}\right]$ contains $x_{i}$ displacement of the $i$ th floor of Building B relative to ground $(i=1,2, \ldots, m)$.

For feedback control in Example 2, the control force in Equation (7) can be written as

$$
U(t)=-G_{d}\left[\begin{array}{c}
X_{1} \\
X_{2}
\end{array}\right]-G_{v}\left[\begin{array}{c}
\dot{X}_{1} \\
\dot{X}_{2}
\end{array}\right]-G_{a} C_{s a}\left[\begin{array}{c}
X_{1} \\
X_{2} \\
\dot{X}_{1} \\
\dot{X}_{2}
\end{array}\right]
$$

where

$$
\begin{aligned}
C_{s a} & =\left[\begin{array}{ll}
-M_{c l}^{-1} K_{c l} & -M_{c l}^{-1} C_{c l}
\end{array}\right] \\
M_{c l} & =M+D G_{a}, K_{c l}=K+D G_{d}, C_{c l}=C+D G_{v}
\end{aligned}
$$

Rearranging Equation (A5), the control force can be shown as $U(t)=-G_{z} X . X$ is a state vector in Equation (5). $G_{z}$ is the gain matrix, which can be obtained as

$$
G_{z}=\left[\begin{array}{ll}
G_{d} & G_{v}
\end{array}\right]+G_{a} C_{s a}
$$

According to the chosen feedback in this study, the gain matrix can be written for Example 2 as

$$
\begin{aligned}
G_{d} & =\left[\begin{array}{llllllllllll}
0 & 0 & 0 & 0 & 0 & G_{d 1} & 0 & 0 & 0 & 0 & 0 & G_{d 2}
\end{array}\right] \\
G_{v} & =\left[\begin{array}{llllllllllll}
0 & 0 & 0 & 0 & 0 & G_{v 1} & 0 & 0 & 0 & 0 & 0 & 0
\end{array}\right] \\
G_{a} & =\left[\begin{array}{llllllllllll}
0 & 0 & 0 & 0 & 0 & 0 & 0 & 0 & 0 & 0 & 0 & G_{a 1}
\end{array}\right]
\end{aligned}
$$

where $G_{d 1}, G_{d 2}, G_{v 1}$ and $G_{a 1}$ are gains to be determined in Example 2. The closed loop system can be obtained as

$$
\dot{X}=A_{c l} X+H \ddot{x}_{g}
$$

where $A_{c l}=A-B G_{z}$ and the feedback is the top floor of displacement of both buildings, the velocity of the top floor of Building A and the absolute acceleration of the top floor of Building B, as shown in Equation (A8). Regulated output $C_{w}$ is chosen as interstorey drifts, the top floor displacement of both buildings and the control force to obtain the optimum controller gains. 